\title{
Sound characterization and fine-scale spatial mapping of an estuarine soundscape in the southeastern USA
}

\author{
Claire Mueller ${ }^{1, \#}$, Agnieszka Monczak ${ }^{1,2, \#, ~ J a m i l e h ~ S o u e i d a n ~}{ }^{1}$, Bradshaw McKinney ${ }^{1}$, \\ Somers Smott ${ }^{1,3}$, Tony Mills ${ }^{4}$, Yiming $\mathrm{Ji}^{5}$, Eric W. Montie ${ }^{1, \#, *}$
}

${ }^{1}$ Department of Natural Sciences, University of South Carolina Beaufort, Bluffton, SC 29909, USA

${ }^{2}$ Institute of Biological and Environmental Sciences, University of Aberdeen, Aberdeen AB24 2TZ, UK

${ }^{3}$ Rosenstiel School of Marine and Atmospheric Science, University of Miami, Miami, FL 33149, USA

${ }^{4}$ The Lowcountry Institute, Okatie, SC 29909, USA

${ }^{5}$ Department of Computer Science, University of South Carolina Beaufort, Bluffton, SC 29909, USA

ABSTRACT: Estuaries are areas known for biological diversity, and their soundscapes reflect the acoustic signals used by organisms to communicate, defend territories, reproduce, and forage in an environment that has limited visibility. These biological sounds may be rhythmic in nature, spatially heterogeneous, and can provide information on habitat quality. The goal of our study was to investigate the temporal and spatial variability of sounds in Chechessee Creek (Stns CC1 and CC2) and an adjacent saltwater impoundment (Great Salt Pond, GSP) in South Carolina, USA, from April to November 2016. Fixed recording platforms revealed that sound pressure levels (SPLs) were significantly higher in CC1 and CC2 compared to GSP. We detected some biological sounds in GSP (snapping shrimp genera Alpheus and Synalpheus, silver perch Bairdiella chrysoura, oyster toadfish Opsanus tau, spotted seatrout Cynoscion nebulosus, Atlantic croaker Micropogonias undulatus, and American alligator Alligator mississippiensis); however, biological sound was much more prevalent in $\mathrm{CC} 1$ and CC2. In Chechessee Creek, snapping shrimp, oyster toadfish, and spotted seatrout sounds followed distinct temporal rhythms. Using these data, we conducted spatial passive acoustic surveys in Chechessee Creek. We discovered elevated high frequency SPLs (representing snapping shrimp acoustic activity) near an anti-erosion wall, as well as increased low frequency SPLs (indicating spotted seatrout spawning aggregations) near the anti-erosion wall and at the mouth of Chechessee Creek. This study has demonstrated the utility of combining stationary and mobile recording platforms to detect acoustic hotspots of biological sounds.

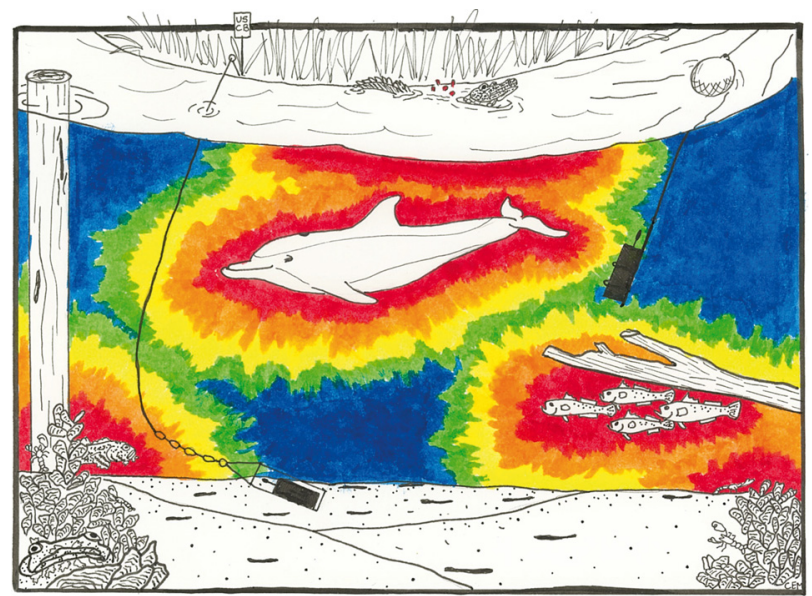

Studying soundscapes can provide acoustic behavior measurements at multiple levels of biological complexity at fine spatial and temporal scales.

Illustration: C. Mueller

KEY WORDS: Estuaries · Soundscapes · Tidal creek · Saltwater impoundment · Snapping shrimp · Fish · Hydrophone surveys

\section{INTRODUCTION}

Soundscape ecology is an emerging field that studies the biological (biophony), geophysical (geophony), and anthropogenic sounds (anthrophony) that are produced in a landscape (Krause et al. 2011, Pijanowski et al. 2011). In marine ecosystems, these sounds often vary spatially and temporally, which can provide key insight into the foraging behavior of

() The authors 2020. Open Access under Creative Commons by Attribution Licence. Use, distribution and reproduction are unrestricted. Authors and original publication must be credited. 
invertebrates (Bohnenstiehl et al. 2016, Monczak et al. 2019), fish spawning patterns (e.g. LowerreBarbieri et al. 2008, Montie et al. 2015, 2016, 2017 , Monczak et al. 2017), and the foraging and communication of apex predators (Herzing 1996, Janik 2000, McCowan \& Reiss 2001, Vergne et al. 2009, Rosenblatt et al. 2013, Monczak et al. 2019). Current technology allows long-term monitoring of marine soundscapes, which can provide critical data on species presence and key behaviors over various time scales (i.e. seasonal, lunar, daily, and tidal rhythms). By listening to and quantifying the behaviors of soniferous organisms, soundscape ecology can provide an additional metric to gauge habitat quality and the health of marine ecosystems.

Findings indicate that estuaries in the southeastern USA are rich in biological sound. These sounds can include the acoustic behavior of snapping shrimp (Alpheus and Synalpheus spp.) (Bohnenstiehl et al. 2016, Monczak et al. 2019); the courtship calls of ecologically important fish species such as silver perch Bairdiella chrysoura, oyster toadfish Opsanus tau, and Atlantic croaker Micropogonias undulatus, and economically important species such as black drum Pogonias cromis, spotted seatrout Cynoscion nebulosus, and red drum Sciaenops ocellatus (Luczkovich et al. 2008a, Montie et al. 2015, Monczak et al. 2017); and vocalizations of apex predators such as bottlenose dolphins Tursiops truncatus (e.g. Monczak et al. 2019) and American alligators Alligator mississippiensis. Studies that have described the soundscapes of estuaries in the USA include a comparison of oyster Crassostrea virginica reefs and soft-bottom habitats in Pamlico Sound, North Carolina (Lillis et al. 2014a); soundscape patterns and processes in a shallow estuarine reserve in Middle Marsh, North Carolina (Ricci et al. 2016); and temporal rhythms of the soundscape of a deep tidal river estuary, the May River, South Carolina (Monczak et al. 2019).

Soundscape data can provide an understanding of what organisms experience acoustically as they move through an estuary. In fact, there is some evidence that sound gradients serve as settlement cues to organisms that pass through the soundscape. Field experiments showed that oyster larval recruitment was significantly higher on larval collectors exposed to oyster reef sounds compared to controls with no sounds (Lillis et al. 2015). Overall, habitats rich in biological sound may be more favorable for spawning, residence, and settlement by invertebrates and fish because they provide acoustic cues indicating that these habitats are rich in resources (Mann et al. 2007). Thus, fine-scale acoustic mapping of estuaries at appropriate times is necessary because many organisms produce sound only during specific seasons or during specific times of the day.

Recent reports have shown that estuarine soundscapes exhibit distinct temporal rhythms that vary over tidal, daily, lunar, and seasonal time scales (Ricci et al. 2016, Monczak et al. 2017, 2019). To advance our knowledge and understanding of sound level gradients in an estuary, we experimented with a lowcost method to create spatial heat maps of biological sound within specific periods. We focused our studies on Chechessee Creek and an adjacent saltwater impoundment in South Carolina, USA. The specific objectives of this study were to (1) compare low frequency (i.e. more indicative of sounds originating from fish) and high frequency (i.e. more indicative of snapping shrimp snaps) sound pressure levels (SPLs) between Chechessee Creek (Stns CC1 and CC2) and a saltwater impoundment (Great Salt Pond, GSP); (2) characterize the types of biological sounds and temporal patterns in these habitats from acoustic data obtained from stationary recorders; and (3) perform fine-scale spatial mapping of low and high frequency SPLs in Chechessee Creek using a towable recorder. We argue that both stationary fixed recorders and mobile recording platforms are best used in tandem as a means to understand the spatial variation in the soundscape because some species follow specific patterns in sound production that are correlated with temporal and environmental variables.

\section{MATERIALS AND METHODS}

\subsection{Study site}

We performed a 6 mo acoustic monitoring study of Chechessee Creek (Stns CC1 and CC2) and a saltwater impoundment (GSP) in South Carolina, USA (Fig. 1). This subtidal creek is between 3 and $15 \mathrm{~m}$ deep, $\sim 6 \mathrm{~km}$ long, and ranges from $\sim 0.07 \mathrm{~km}$ wide at the source to $\sim 0.60 \mathrm{~km}$ wide at the mouth where it empties into the Chechessee River. A variety of habitats border the creek including oyster reefs, vast expanses of smooth cord grass Spartina alterniflora, docks, and rock anti-erosion walls. The creek has a strong tidal range of $2.3-3.1 \mathrm{~m}$. GSP is located approximately $0.27 \mathrm{~km}$ inland from Chechessee Creek and is connected to the Chechessee Creek on the north end. At this end, control structures are used to raise and lower the water levels in the pond to promote flushing and provide an influx of invertebrate and fish species. At the south end of the pond, water 


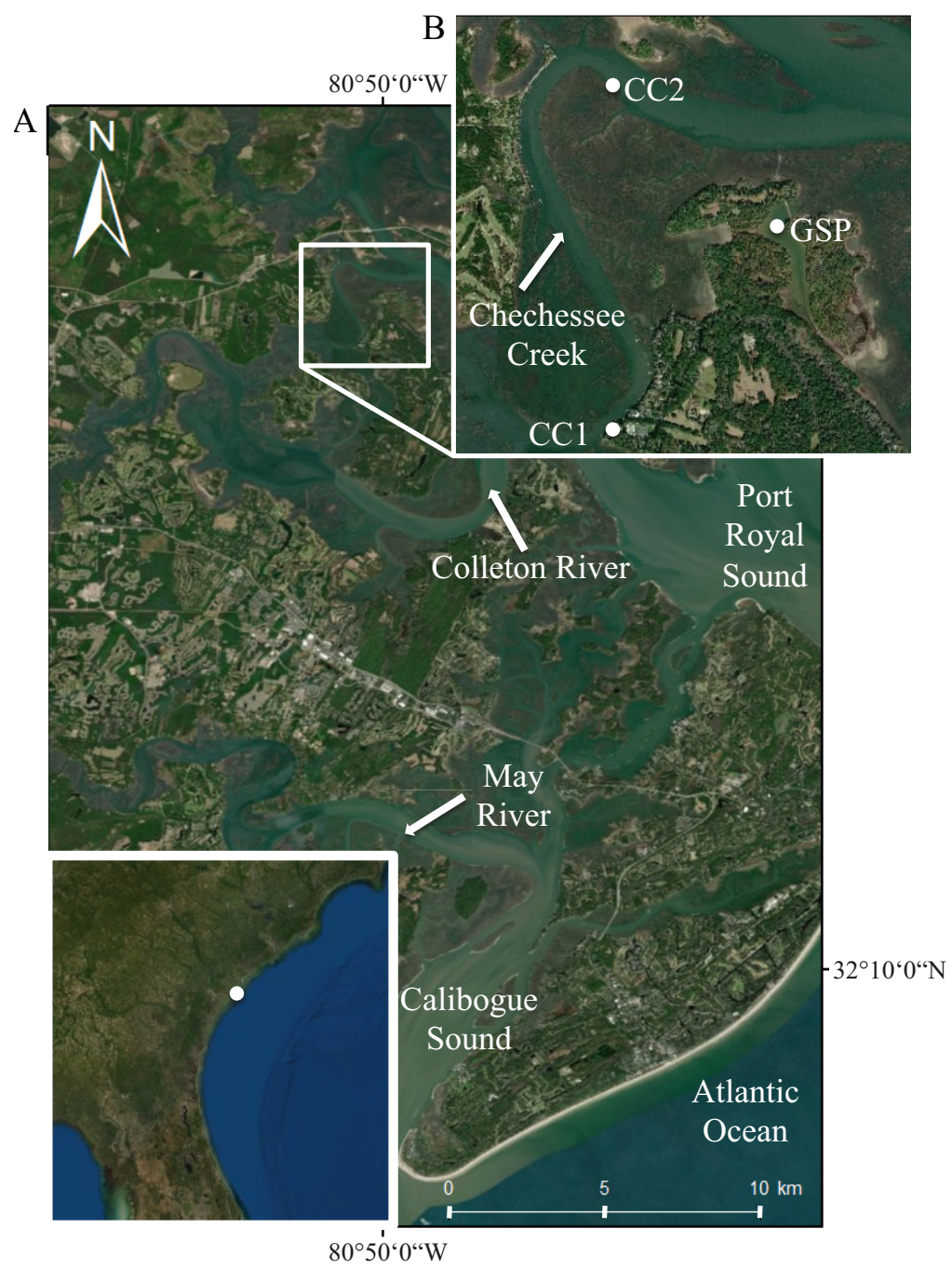

Fig. 1. Chechessee Creek (Stns CC1 and CC2) and the saltwater impoundment (the Great Salt Pond, GSP) in Okatie, South Carolina, USA. (A) Waterways near Chechessee Creek. Inset: Chechessee Creek, South Carolina (white dot), showing the approximate location of this creek in reference to the US East Coast. (B)

Locations of the stationary recording platforms at Stns CC1, CC2, and GSP

scape at CC1, CC2, and 1 location in the GSP over 2 deployments between 28 April and 3 November 2016, following methods previously described (Monczak et al. 2017, 2019) (Fig. 1). Hydrophones had a sensitivity of $-185 \mathrm{dBV} \mu \mathrm{Pa}^{-1}$ with a flat frequency response between $\sim 0.1$ and $30 \mathrm{kHz}$. DSG recorders had a gain of $20 \mathrm{~dB}$ and were scheduled to record the underwater environment for $2 \mathrm{~min}$ every $20 \mathrm{~min}$ standard time at a sampling rate of $80 \mathrm{kHz}$. In order to minimize noise artefacts, the DSG-Ocean recorders were mounted in custom-built instrument frames (Mooring Systems) (Fig. 2A). We encased water level and temperature loggers (HOBO 100-Foot Depth Water Level Data Logger U20-001-02-Ti and HOBO Water Temperature Pro v2 U22-001; Onset Computer Corporation) in PVC pipes and attached them to the instrument frames using zip ties. The HOBO loggers measured water depth every $10 \mathrm{~min}$ and water temperature every hour. Depth loggers were not deployed in GSP because it is not a tidal system. The DSG-Ocean recorders, instrument frames, and PVC pipes were painted with antifouling paint (Trilux 33; West Marine). We deployed the DSG-Ocean recorders approximately $10 \mathrm{~m}$ from the shoreline at the bottom of the creek or pond. This was accomplished by attaching a $7 \mathrm{~m}$ galvanized chain to the instrument frame, attaching that chain to a line, and tying that line to an auger on shore. Upon deployment,

flows outward through 2 culverts before emptying into the salt marsh and the Colleton River. The pond is $0.10 \mathrm{~km}^{2}$ in area, has a $2.27 \mathrm{~km}$ perimeter, and is approximately $1.25 \mathrm{~m}$ deep. GSP was stocked with numerous fish species between June 2015 and February 2016 (Table S1 in the Supplement at www.intres.com/articles/suppl/m645p001_supp/).

\subsection{Acoustic and environmental data collection}

\subsubsection{Fixed recording platforms}

We deployed acoustic recorders (DSG-Ocean recorders; Loggerhead Instruments) to monitor the sound- all frames were forced on their sides by pulling the line taught. This setup minimized moving parts and noise artefacts and added protection for the recorders and loggers. The recorders were serviced between 28 July and 4 August 2016.

\subsubsection{Mobile recording platforms}

In order to create maps of sound levels in Chechessee Creek, we conducted spatial passive acoustic surveys in which we towed a DSG-Ocean recorder (set to a continuous recording cycle) in the direction of the tidal flow (Fig. 2B). The DSG-Ocean recorder was attached to a frame which was then 

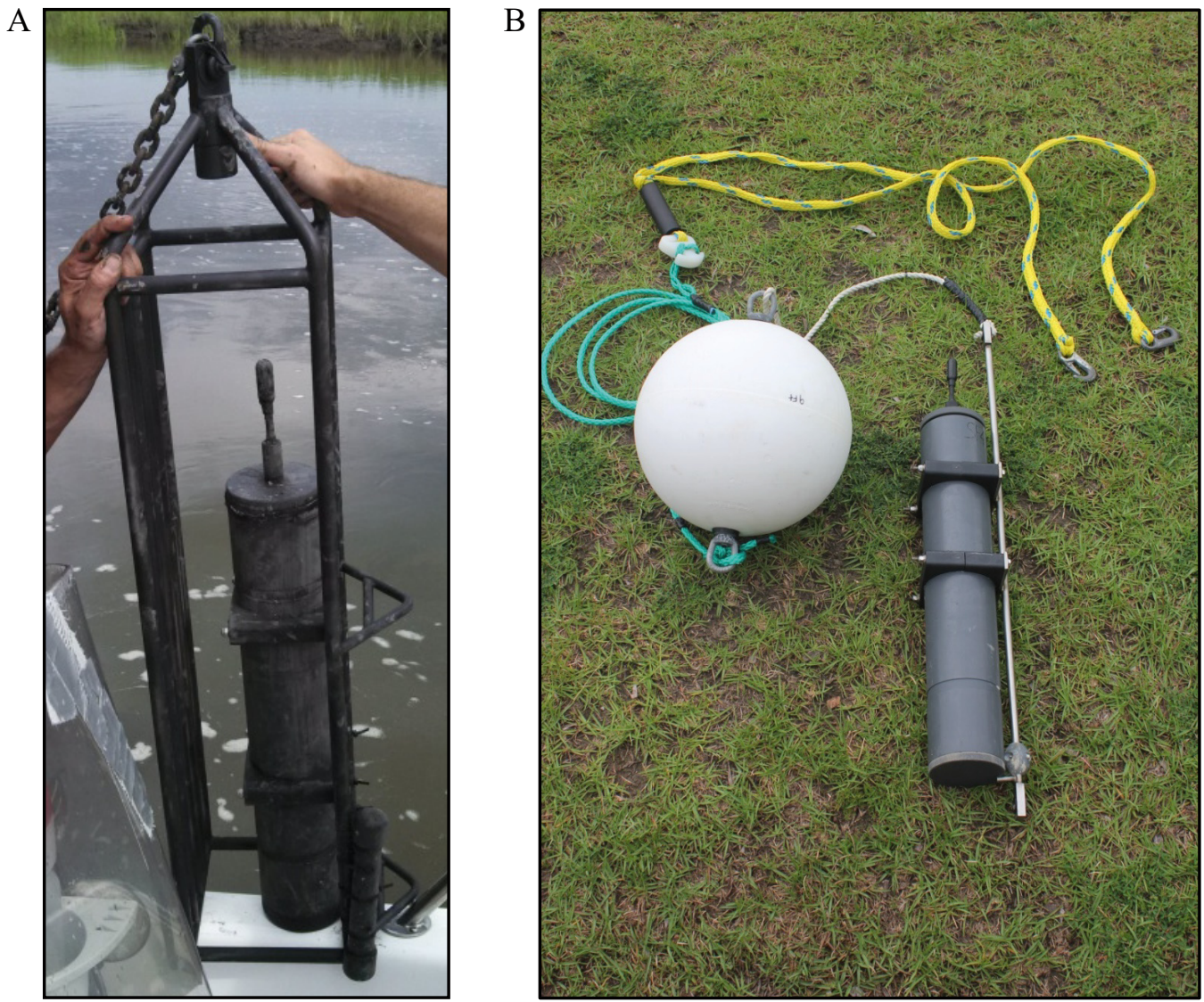

Fig. 2. (A) Fixed DSG-Ocean acoustic recorder inside instrument frame. These instruments were deployed at the bottom of Chechessee Creek at Stns CC1 and CC2 and in the Great Salt Pond. (B) Mobile recording platform used for passive acoustic surveys. This recorder was suspended in an instrument frame under the plastic float and towed behind a boat using an electric trolling motor

suspended in the water column at a depth of $3 \mathrm{~m}$ using a line tied to a hard plastic float (Mooring Systems) (Fig. 2B). The buoy was then attached to a $4 \mathrm{~m}$ line and affixed to the boat using a heavy duty towing harness (West Marine). We tested different boat propulsion methods (90 horse power [hp] Yamaha Four Stroke versus a $1 \mathrm{hp}$ Minn Kota EO TransomMount Electric Outboard Motor) and their contributions to ambient noise levels (Fig. S1). We concluded that the trolling motor was the most effective method for performing the passive acoustic surveys because it decreased the background noise associated with propulsion compared to the Yamaha Four Stroke motor (Fig. S1). The ambient SPL in the creek was on average $119 \mathrm{~dB}$ re $1 \mu \mathrm{Pa} \pm 4 \mathrm{~dB}$ (mean $\pm \mathrm{SD}$ ). The outboard engine on the boat with ambient noise had a mean SPL of $147 \mathrm{~dB}$ re $1 \mu \mathrm{Pa} \pm$ $4 \mathrm{~dB}$, while the trolling motor with ambient noise had an average SPL of $133 \mathrm{~dB}$ re $1 \mu \mathrm{Pa} \pm 3 \mathrm{~dB}$. We found that the trolling motor was significantly quieter than the outboard engine $(t$-test $; \mathrm{p}<0.05)$.
Thus, in order to maintain control of the boat and the mobile recording platform, we used a trolling motor during the sound-mapping surveys at a uniform power of $11 \mathrm{~kg}$ of thrust. With the tidal flow, the boat towed the recording platform at a speed of $1.6-3.2 \mathrm{~km} \mathrm{~h}^{-1}$.

Dates and times for surveys were determined using the knowledge of fish calling and chorusing patterns from passive acoustic data collected in the May River, South Carolina (Monczak et al. 2017, 2019). Surveys moved in the direction of the tidal current to minimize flow noise. Therefore, optimal timing of the tides and the calling patterns of fish were both taken into consideration when selecting evenings to perform mapping surveys. We conducted 5 surveys in Chechessee Creek (Table S2). The DSG-Ocean recorder was set to record continuously at a sampling rate of $80 \mathrm{kHz}$. Acoustic files were saved as 2 min recordings on a 128 GB SD card. These files were then batch-converted into 'wav' files using DSG2wav ${ }^{\circledR}$ software (Loggerhead Instruments). Dur- 
ing each tow, we recorded the location of our route using a Garmin 76CS GPS, which was time-synced to the DSG-Ocean recorder. The GPS recorded latitude and longitude locations every $30 \mathrm{~s}$. GPS tracks were downloaded to BaseCamp (Garmin) and then exported to Microsoft Excel. Depth was recorded manually every $5 \mathrm{~min}$ with a handheld digital depth sounder (Vexilar). Environmental parameters were taken using an YSI 556 Handheld Multiparameter Instrument (YSI/Xylem) every $5 \mathrm{~min}$.

\subsection{Acoustic analysis}

\subsubsection{Fixed recording platforms}

We collected a total of 39308 acoustic files. We performed root mean square (rms) SPL analyses on each 2 min wav file for broadband $(1-40000 \mathrm{~Hz}$ ), low $(50-1200 \mathrm{~Hz})$ and high $(7000-40000 \mathrm{~Hz})$ frequency bandwidths using MATLAB version 2014a (Mathworks) scripts previously discussed (Monczak et al. 2019). The broadband bandwidth was designed to provide a measure of total sound levels at each station. Although some recorders produce noise from $0-50 \mathrm{~Hz}$, the bandwidth of $1-40 \mathrm{kHz}$ was kept uniform across all stations. SPLs in the low frequency bandwidth were designed to include the peak frequencies of specific fish calls, lower frequencies of snapping shrimp sounds, bottlenose dolphin vocalizations, and noises of physical and anthropogenic origin. SPLs in the high frequency bandwidth included snapping shrimp snaps, high frequency vocalizations of bottlenose dolphins, and noise associated with anthropogenic and physical sources. We determined the rms SPL for each wav file using the equation from Merchant et al. (2015):

$$
\begin{gathered}
S=h+g+20 \log _{10}\left(1 / V_{\text {adc }}\right) \\
b=20 \log _{10}\left\{\operatorname{sqrt}\left[\operatorname{mean}\left(y^{2}\right)\right]\right\} \\
a=b-S
\end{gathered}
$$

where $a$ is the calibrated sound level in $\mathrm{dB}$ re $1 \mu \mathrm{Pa}$; $b$ is the uncorrected signal; $S$ is a correction factor; $h$ is the hydrophone sensitivity (i.e. $-185 \mathrm{dBV} \mathrm{PPa}^{-1}$ ); $g$ is the DSG gain (i.e. $20 \mathrm{~dB}$ ); $V_{\text {adc }}$ is the analog-to-digital conversion (i.e. 1 volt); and $y$ is the signal. For each station, we determined the mean $( \pm \mathrm{SD})$ for broadband, low, and high frequency rms SPLs for each 2 min file over the entire deployment timeframe. To understand the temporal rhythms in SPL, we created rms SPL heat maps of each wav file versus date and hour of day, along with the correspon- ding temperature. In addition, to count snapping shrimp snaps we used a custom, feature-based MATLAB script that reported the number of snaps per 2 min wav file following the methods outlined in previous studies (Monczak et al. 2019). The snap detector featured an amplitude threshold set to 0.9 in order to keep the detection range relatively constant. Heat maps of snap rate of each 2 min wav file versus date and hour of day, along with corresponding water temperature, illustrated the temporal rhythms of snapping. For all analyses, we eliminated files that contained vessel noise, rain, or chain artefacts in order to exclude the influence of anthrophonic and geophonic noise sources.

To identify and quantify fish calls, bottlenose dolphin vocalizations, and other biological sounds, wav files were manually reviewed using Adobe Audition CS5.5 software (Adobe Systems). In Adobe Audition, we reviewed spectrograms in $10 \mathrm{~s}$ windows for each 2 min wav file in order to identify sound-producing organisms. The spectral resolution was set to 2048 in Adobe Audition because this setting created the clearest spectrogram, which allowed us to view call signatures clearly. We provided spectrograms of species calls and vocalizations in Adobe Audition because observers used this program to review files; in addition, this software program provided high quality spectrograms (i.e. better than MATLAB), which assists with acoustic signature recognition. To assist the reader in identifying calls and vocalizations to species, we provide signature audio files in the Supplement (audio files 1-8) at www.int-res.com/articles/ suppl/m645p001_supp/. For fish, we identified calls by comparing acoustic signatures to spectrograms published in other studies (Tavolga 1958, Luczkovich et al. 1999, Sprague 2000, Rountree et al. 2006, Monczak et al. 2017). To gauge the amount of fish calling that occurred in each wav file, a scoring system was used (i.e. $0=$ no calls; $1=$ one call detected; $2=$ multiple calls; $3=$ overlapping calls or chorus) following the methods outlined in previous studies (Luczkovich et al. 2008b, Monczak et al. 2017). Dolphin vocalizations were counted per 2 min wav file as the number of echolocation bouts, burst pulses, and whistles (Herzing 1996). Echolocation, or click trains, are clusters of clicks lasting anywhere from 50-80 $\mu$ s, while burst pulses have harmonic bands that are highly repetitive (Hendry 2004). Whistles consist of a single band that can have several frequency fluctuations, or contours (Janik 2000). We totaled the number of files with different fish calls, dolphin vocalizations, and unknown biological sounds at each station. We summed fish calling intensity scores per day centered on midnight 
(i.e. from 12:00 to 11:40 h the next day, Eastern Standard Time, EST) and plotted these sums with corresponding water temperature, hours of daylight, and lunar cycle versus the date.

\subsubsection{Mobile recording platforms}

To create spatial heat maps of biological sound, we calculated high (7000-40 $000 \mathrm{~Hz}$ ) and low (50-1200 Hz) frequency SPLs for each second of the recorded wav files (i.e. not the rms SPL of the 2 min wav file) during the spatial passive acoustic surveys. We used a MATLAB-based script in 'PAMGuide' to calculate the 1 s SPL values (Merchant et al. 2015). We then manually averaged the low and high frequency SPLs every 30 s using Microsoft Excel, which corresponded to the sampling interval of the GPS. In separate low and high frequency heat maps, these SPL averages were plotted along the survey track using ArcMap 10.5 (ESRI). The SPL range used in the legend was determined by taking the lowest and highest values from all of the surveys and assigning colors to those data. The point size for each $30 \mathrm{~s}$ segment was $22 \mathrm{~m}$, which was determined by taking the mean distance travelled in $30 \mathrm{~s}$ during the survey and then doubling this distance to ensure visibility and accuracy in the heat maps. In all cases, times represent EST without the incorporation of daylight savings time.

\subsection{Statistical analyses}

We performed general linear model (GLM) tests using SPSS Statistics 24 (IBM) to evaluate the influence of location, month, lunar cycle, day/night, tidal phase, and temperature anomaly on broadband, low, and high frequency SPLs. To investigate factors that influence snapping shrimp snap rate, we performed a similar GLM but included interactive factors (location $\times$ tidal phase and month $\times$ day/night). We performed a GLM to investigate the influence of location, month, lunar phase, tidal range, and temperature anomaly on oyster toadfish and spotted seatrout calling. To classify the lunar cycle, we used 4 categories: new moon (lunar days 27-4), first quarter (lunar days 5-11), full moon (lunar days 12-19), and third quarter (lunar days 20-26) (Eggleston et al. 1998, Monczak et al. 2017). Temperature anomalies were determined by subtracting $30 \mathrm{~d}$ moving averages from the observed water temperature. We used local sunrise and sunset times to determine day and night. Tidal phases were determined using depth data and were categorized into high tide (samples with the deepest depth within a tidal cycle), falling tide (samples between high and low tide), low tide (samples with the shallowest depth), and rising tide (samples between low and high tide).

We assessed the normality of the dependent variables by assessing histograms, skewness, and kurtosis. We assumed the data were normally distributed if the absolute value of skewness was $<2$ and kurtosis was $<7$ (Ghasemi \& Zahediasl 2012, Kim 2013). We performed additional tests to assess significance between groups if categorical variables had a significant influence on the dependent variable. If assumptions were not violated, Tukey's HSD tests were used; if assumptions were violated, Dunnett's $C$-tests were performed.

\section{RESULTS}

\subsection{Spatial and temporal comparisons of SPLs}

Based on the results of SPL analysis using data from our stationary DSG-Ocean recorders, there were spatial and temporal differences among stations. Our observations showed that Chechessee Creek (Stns CC1 and CC2) was louder than the saltwater impoundment (Stn GSP) (Figs. 3 \& 4). Results from the broadband analyses showed that GSP mean $( \pm \mathrm{SD})$ SPL $(118 \pm 4 \mathrm{~dB}$ re $1 \mu \mathrm{Pa})$ was lower than CC1 $(120 \pm$ $4 \mathrm{~dB})$ and CC2 $(120 \pm 4 \mathrm{~dB})$ SPLs (Dunnett's post hoc test, $\mathrm{p}<0.05)$. The mean low frequency SPL for GSP (92 $\pm 8 \mathrm{~dB}$ ) was significantly lower than the SPLs for CC1 $(108 \pm 5 \mathrm{~dB})$ and CC2 $(105 \pm 8 \mathrm{~dB})$ (Dunnett's post hoc test, $\mathrm{p}<0.05)$. The same results were observed for mean high frequency, with SPLs of the GSP (96 $\pm 6 \mathrm{~dB}$ ) significantly lower than SPLs of CC1 $(114 \pm 2 \mathrm{~dB})$ and CC2 (113 $\pm 1 \mathrm{~dB})$ locations (Dunnett's post hoc test, $\mathrm{p}<0.05)$. Water quality was similar among CC1, CC2, and GSP (Table S3). The depth of Chechessee Creek varied from 4.09-7.15 m, while GSP was consistently around $1.25 \mathrm{~m}$ deep.

The temporal patterns observed among the locations were significantly influenced by month, lunar phase, tidal phase, and temperature anomaly for broadband, low, and high frequency rms SPLs (Table 1). In addition, low frequency SPLs were influenced by day/night cycles (Table 1). The most striking patterns occurred in Chechessee Creek; low frequency SPLs were highest in the summer months (June, July, and August) during the night and followed an oscillating pattern (Fig. 3A,B; Dunnett's post hoc test, p < 0.05). In the $1^{\text {st }}$ and $3^{\text {rd }}$ quarter of the lunar cycle, SPLs in the low frequency bandwidth remained at a higher 

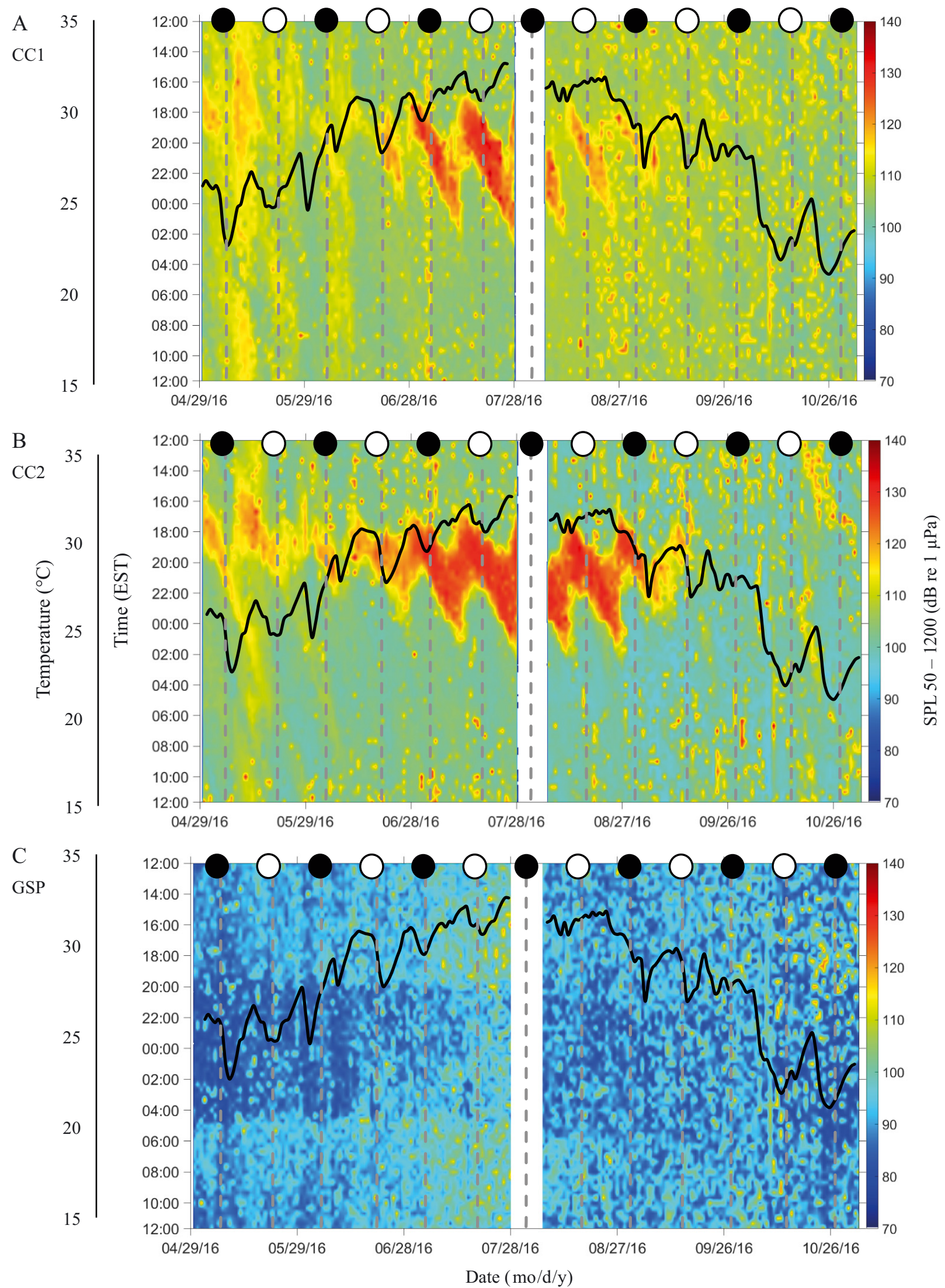

Fig. 3. Root mean square sound pressure levels (SPLs) for each 2 min wav file every 20 min in the low frequency bandwidth (50-1200 Hz) versus date and time (from noon to noon of the next day; Eastern Standard Time) at Stns (A) CC1; (B) CC2; and (C) GSP. Breaks in data (white block) indicate recorder service. Warmer colors: higher SPLs. Black line: water temperature. Moon phases are indicated by black (new moon) and white (full moon) circles 

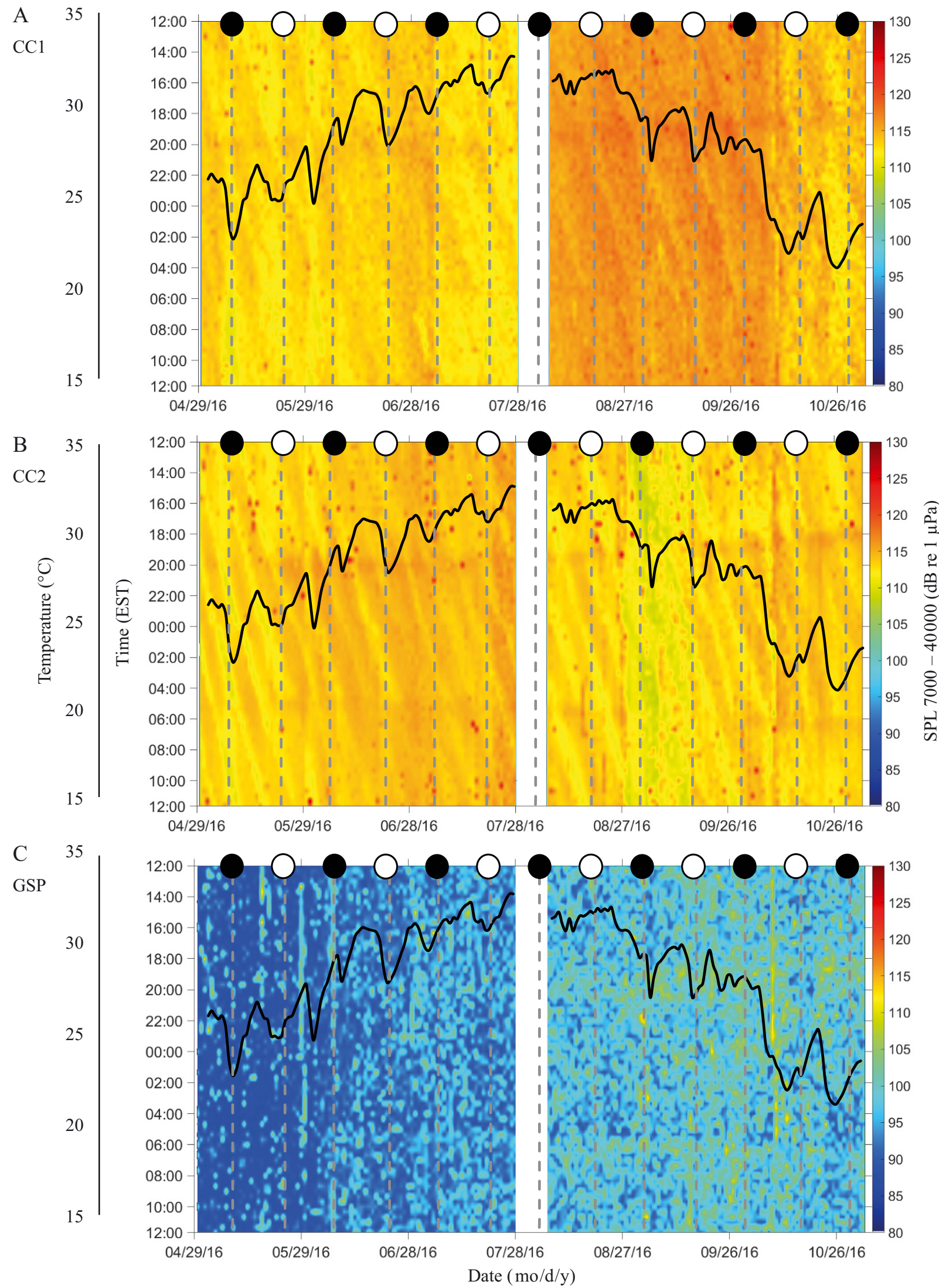

Fig. 4. Root mean square sound pressure levels (SPLs) for each 2 min wav file every 20 min in the high frequency bandwidth (7000-40000 Hz) versus date and time (from noon to noon of the next day; EST) at stations (A) CC1; (B) CC2; and (C) GSP. Breaks in data (white block) indicate recorder service. Warmer colors: higher SPLs. Black line: water temperature. Moon phases are indicated by black (new moon) and white (full moon) circles 
Table 1. General linear model results investigating the influence of specific factors on sound pressure levels in Chechessee Creek and Great Salt Pond, South Carolina. Values in bold are significant at $\mathrm{p}<0.05$

\begin{tabular}{|lrrr|}
\hline & df & \multicolumn{1}{c|}{$F$} & \multicolumn{1}{c}{$p$} \\
\hline SPL 1-40000 Hz & & & \\
Location & 2 & 312.13 & $<\mathbf{0 . 0 1}$ \\
Month & 7 & 197.12 & $<\mathbf{0 . 0 1}$ \\
Lunar phase & 3 & 89.73 & $<\mathbf{0 . 0 1}$ \\
Tidal phase & 3 & 245.39 & $<\mathbf{0 . 0 1}$ \\
Day/night & 1 & 0.04 & 0.83 \\
Temperature anomaly & 1 & 418.52 & $<\mathbf{0 . 0 1}$ \\
$\mathrm{R}^{2}$ & 0.15 & & \\
SPL 50-1200 Hz & & & \\
Location & 2 & 7227.32 & $<\mathbf{0 . 0 1}$ \\
Month & 7 & 226.32 & $<\mathbf{0 . 0 1}$ \\
Lunar phase & 3 & 13.79 & $<\mathbf{0 . 0 1}$ \\
Tidal phase & 3 & 4.61 & $<\mathbf{0 . 0 1}$ \\
Day/night & 1 & 354.95 & $<\mathbf{0 . 0 1}$ \\
Temperature anomaly & 1 & 9.08 & $<\mathbf{0 . 0 1}$ \\
$\mathrm{R}^{2}$ & 0.55 & & \\
SPL 7000-40000 Hz & & & \\
Location & 2 & 39543.10 & $<\mathbf{0 . 0 1}$ \\
Month & 7 & 1089.51 & $<\mathbf{0 . 0 1}$ \\
Lunar phase & 3 & 32.22 & $<\mathbf{0 . 0 1}$ \\
Tidal phase & 3 & 8.30 & $<\mathbf{0 . 0 1}$ \\
Day/night & 1 & 0.48 & 0.49 \\
Temperature anomaly & 1 & 1763.33 & $<\mathbf{0 . 0 1}$ \\
$\mathrm{R}^{2}$ & 0.89 & & \\
\hline
\end{tabular}

level for a longer period during the night compared to the new and full moon cycles (Fig. 3A,B).

\subsection{Temporal rhythms of biological sounds}

Snapping shrimp, fish, bottlenose dolphins, and alligator acoustic signals were detected in these soundscapes (Table 2, Figs. 5 \& 6). We provide audio files of these calls and vocalizations in the Supplement (audio files 1-8). Snapping shrimp produced an intense, broadband snap that dominated the soundscape throughout the estuary (Fig. 5A). Sounds produced by soniferous fish included oyster toadfish (Fig. 5B,C), Atlantic croaker (Fig. 5D), silver perch (Fig. 5E), spotted seatrout (Fig. 5F), red drum (Fig. 5G), and an unknown biological sound (Fig. 5H). Calls of apex predators such as bottlenose dolphins were detected in the Chechessee Creek (Fig. 6A-C), while an American alligator vocalization was detected once in GSP (Fig. 6D).

\subsubsection{Snapping shrimp acoustic behavior}

Location, month, lunar phase, tidal phase, day/night, and temperature anomaly significantly influenced

Table 2. Prevalence of fish calling, dolphin vocalizations, and alligator sounds in the Great Salt Pond (GSP) and Chech essee Creek (CC1, CC2), South Carolina. Files with detections: the number of 2 min files with a call detected; percentages were determined by dividing file detections by the total amount of files analyzed (i.e. 12960). Sum intensity: calculated by summing the intensity scores; percentages were determined by dividing the sums by the maximum calling intensity (i.e. 38880). For bottlenose dolphins and alligators, the sum was based on the counted vocalizations

\begin{tabular}{|c|c|c|c|c|c|c|}
\hline & \multicolumn{2}{|c|}{$\longrightarrow \mathrm{CC} 1-$} & \multicolumn{2}{|l|}{$-\mathrm{CC} 2$} & \multirow[b]{2}{*}{$\begin{array}{l}\text { Files with } \\
\text { detections }\end{array}$} & \multirow[b]{2}{*}{$\begin{array}{l}\text { Sum } \\
\text { intensity }\end{array}$} \\
\hline & $\begin{array}{l}\text { Files with } \\
\text { detections }\end{array}$ & $\begin{array}{l}\text { Sum } \\
\text { intensity }\end{array}$ & $\begin{array}{l}\text { Files with } \\
\text { detections }\end{array}$ & $\begin{array}{l}\text { Sum } \\
\text { intensity }\end{array}$ & & \\
\hline \multicolumn{7}{|l|}{ Fish } \\
\hline $\begin{array}{l}\text { Silver perch Bairdiella chrysoura } \\
\text { Oyster toadfish Opsanus tau }\end{array}$ & $116(0.90 \%)$ & $232(0.60 \%)$ & $360(2.78 \%)$ & $761(1.96 \%)$ & $10(0.80 \%)$ & $9(0.02 \%)$ \\
\hline Boatwhistle & $3538(27.30 \%)$ & $6609(17.00 \%)$ & $3579(27.62 \%)$ & $7324(18.84 \%)$ & $61(0.47 \%)$ & $73(0.19 \%)$ \\
\hline Grunt & $1707(13.17 \%)$ & $3080(7.92 \%)$ & $3166(24.43 \%)$ & $5433(13.97 \%)$ & $14(0.11 \%)$ & $18(0.05 \%)$ \\
\hline $\begin{array}{l}\text { Spotted seatrout Cynoscion } \\
\text { nebulosus }\end{array}$ & $2817(21.74 \%)$ & $6471(16.64 \%)$ & $3167(24.44 \%)$ & $7520(19.34 \%)$ & $142(1.10 \%)$ & $200(0.51 \%)$ \\
\hline Red drum Sciaenops ocellatus & $28(0.22 \%)$ & $55(0.14 \%)$ & $9(0.07 \%)$ & $18(0.05 \%)$ & $0(0.00 \%)$ & $0(0.00 \%)$ \\
\hline $\begin{array}{l}\text { Atlantic croaker Micropogonias } \\
\text { undulatus }\end{array}$ & $2676(20.65 \%)$ & $3733(9.60 \%)$ & $2017(15.56 \%)$ & $2637(6.78 \%)$ & $3220(24.85 \%)$ & $4987(12.83 \%)$ \\
\hline \multicolumn{7}{|l|}{ Apex predators } \\
\hline \multicolumn{7}{|l|}{$\begin{array}{l}\text { Bottlenose dolphin Tursiops } \\
\text { truncatus }\end{array}$} \\
\hline Echolocation & $806(6.22 \%)$ & $3627(27.99 \%)$ & $173(1.33 \%)$ & $1207(9.31 \%)$ & $0(0.00 \%)$ & $0(0.00 \%)$ \\
\hline Burst pulses & $153(1.18 \%)$ & $533(4.11 \%)$ & $15(0.12 \%)$ & $53(0.41 \%)$ & $0(0.00 \%)$ & $0(0.00 \%)$ \\
\hline Whistles & $8(0.06 \%)$ & $22(0.17 \%)$ & $3(0.02 \%)$ & $4(0.03 \%)$ & $0(0.00 \%)$ & $0(0.00 \%)$ \\
\hline $\begin{array}{l}\text { American alligator Alligator } \\
\text { mississippiensis }\end{array}$ & $0(0.00 \%)$ & $0(0.00 \%)$ & $0(0 \%)$ & $0(0.00 \%)$ & $1(0.01 \%)$ & $2(0.01 \%)$ \\
\hline \multicolumn{7}{|l|}{ Unknowns } \\
\hline Unknown 1 & $927(7.15 \%)$ & $4506(11.59 \%)$ & $3708(28.61 \%)$ & $6924(17.81 \%)$ & $57(0.44 \%)$ & $76(0.20 \%)$ \\
\hline
\end{tabular}




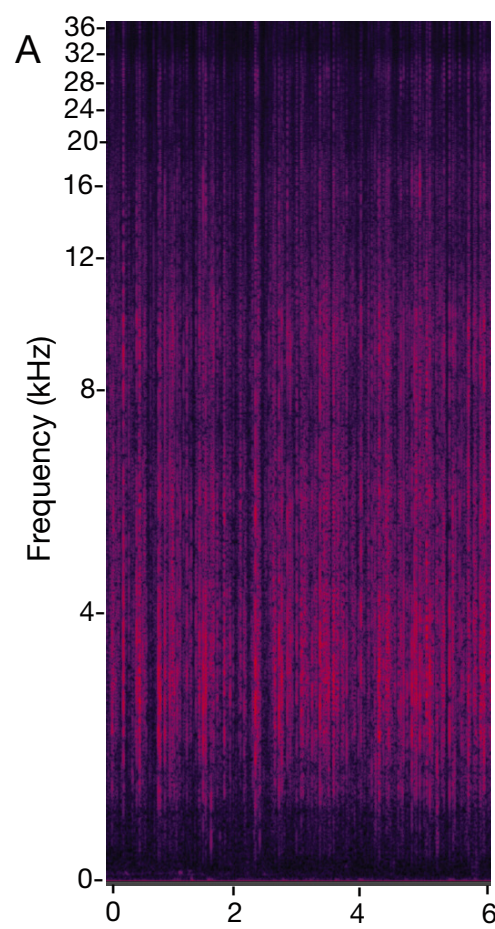

B

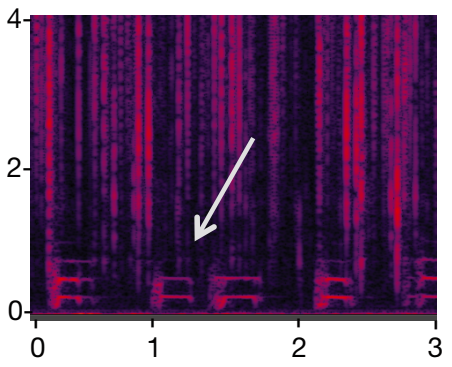

D

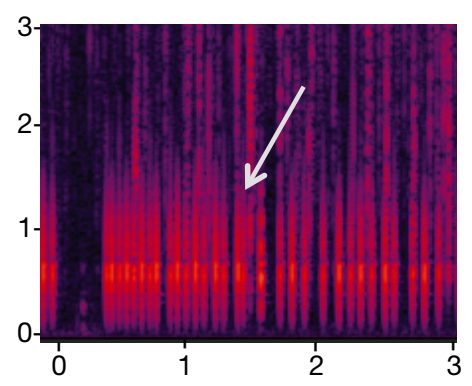

$\mathrm{F}$

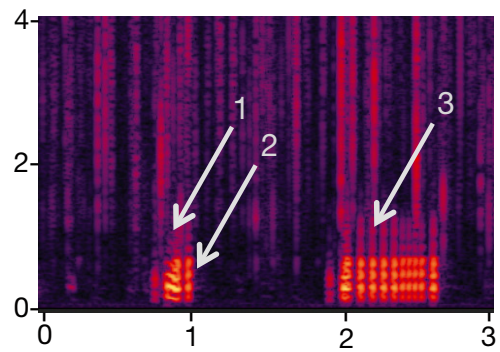

C

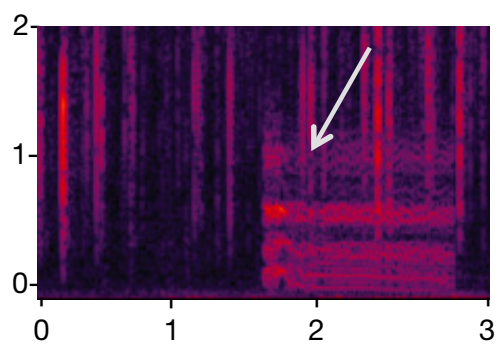

E

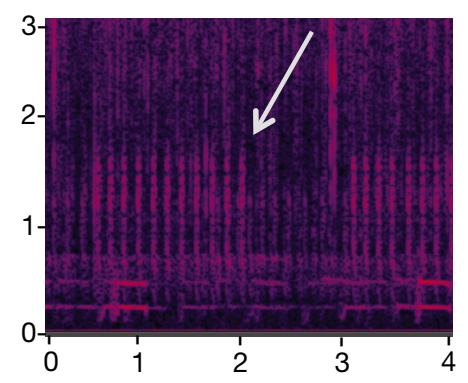

G

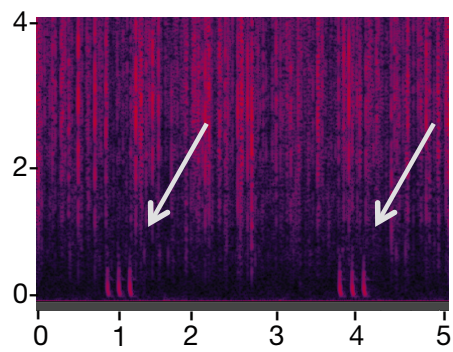

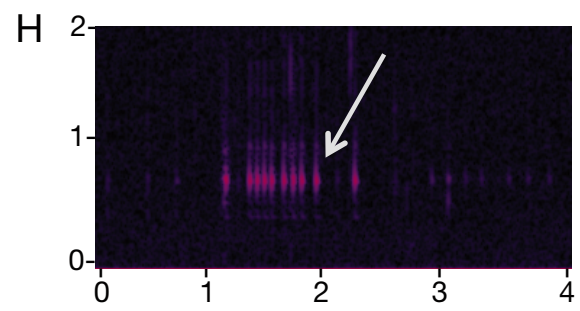

Time (s)

Fig. 5. Spectrograms of known and unknown biological sounds in Chechessee Creek and the Great Salt Pond. (A) Snapping shrimp Alpheus or Synalpheus spp; (B) oyster toadfish Opsanus tau boatwhistle; (C) oyster toadfish grunt; (D) Atlantic croaker Micropogonias undulatus call; (E) silver perch Bairdiella chrysoura calls and oyster toadfish boatwhistle; (F) spotted seatrout Cynoscion nebulosus (1) grunt, (2) knock, and (3) staccato; (G) red drum Sciaenops ocellatus; and (H) unknown call of biological origin, presumably a fish. The respective calls are indicated by the white arrows. Audio files for these species are provided in the Supplement at www.int-res.com/articles/suppl/m645p001_supp/

the snap rate (i.e. snaps per 2 min) (Table 3, Fig. 7). The highest mean snap rate was observed at CC1 $(752 \pm 188$ snaps $)$, followed by CC2 $(471 \pm 243$ snaps), and then GSP $(17 \pm 12$ snaps) (Dunnett's post hoc test, $\mathrm{p}<0.05)$. The snap rate at CC2 dramatically changed on 18 May 2016 due to the move- ment of the recorder to a deeper location and on 8 October 2016 due to Hurricane Matthew, which may have been related to movement of the recorder closer to an oyster reef (Fig. 7B). Tidal phase influenced the snap rate: mean snap rates were significantly higher at low tide $(509 \pm 424$ snaps $)$ than at 


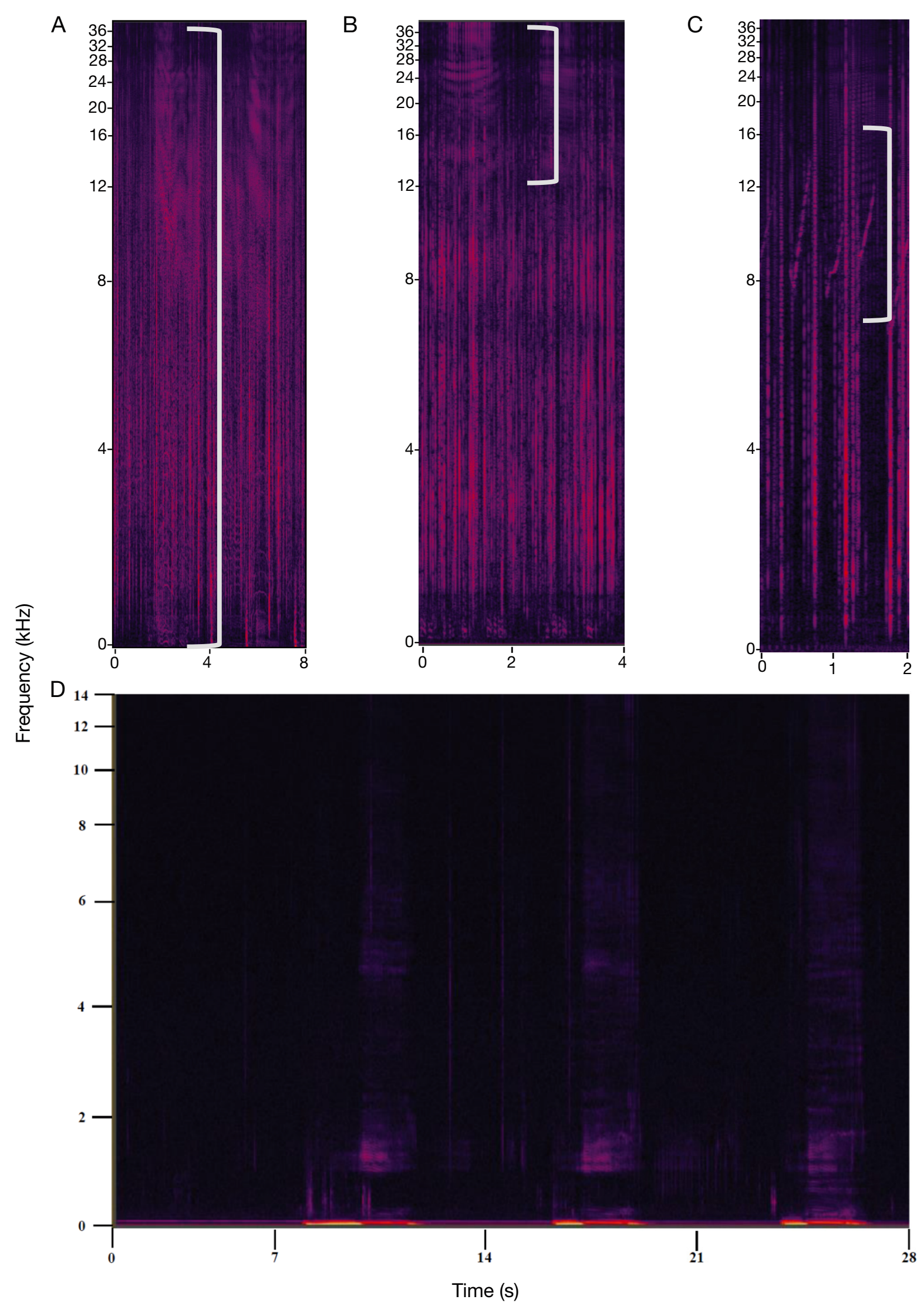

Fig. 6. Spectrograms of vocalizations produced by bottlenose dolphins Tursiops truncatus in Chechessee Creek, including (A) echolocation; (B) burst pulses; and (C) whistles, all indicated by the white brackets. (D) Spectrogram of an American alligator Alligator mississippiensis mating bellow detected in the Great Salt Pond. Audio files for these species are provided in the Supplement 
Table 3. General linear model results investigating the influence of specific variables on snapping shrimp snap rates in Chechessee Creek and the Great Salt Pond. Values in bold are significant at $\mathrm{p}<0.05$

\begin{tabular}{|llrc|}
\hline & df & \multicolumn{1}{c|}{$F$} & $\mathrm{p}$ \\
\hline Location & 2 & 10969.20 & $<\mathbf{0 . 0 1}$ \\
Month & 7 & 1379.01 & $\mathbf{< 0 . 0 1}$ \\
Lunar phase & 3 & 86.00 & $\mathbf{< 0 . 0 1}$ \\
Tidal phase & 3 & 184.78 & $\mathbf{< 0 . 0 1}$ \\
Day/night & 1 & 3.95 & $\mathbf{< 0 . 0 1}$ \\
Temperature anomaly & 1 & 2388.58 & $\mathbf{< 0 . 0 1}$ \\
Location $\times$ tidal phase & 6 & 96.97 & $<\mathbf{0 . 0 1}$ \\
Month $\times$ day/night cycle & 9 & 4.05 & $<\mathbf{0 . 0 1}$ \\
$\mathrm{R}^{2}$ & 0.84 & & \\
\hline
\end{tabular}

high tide (407 \pm 335 snaps) (Dunnett's post hoc test, $\mathrm{p}<0.05$ ). This striking diagonal pattern in snap rates was similar to the tidal pattern observed in Chechessee Creek with increased snapping on the low tide (Figs. $7 \&$ 8). The GSP had no tidal pattern. Increases in snap rates were observed with positive temperature anomalies (Dunnett's post hoc test, $\mathrm{p}<0.05)$.

\subsubsection{Fish calling and chorusing}

No chorusing and few fish calls were detected in the GSP compared to frequent detections at locations CC1 and CC2 (Table 2, Fig. 9). In Chechessee Creek, the deployment timelines of our recorders captured a large portion of the seasonal calling of oyster toadfish and spotted seatrout, so we focused our investigation on these fish. For these species, month, lunar phase, tidal range, and temperature anomaly significantly influenced calling intensity scores (Table 4). Oyster toadfish calls (mean sum calling intensity score per day) were detected at higher levels at $\mathrm{CC} 2$ on average. Within the calling seasons, we recorded the highest levels of calling intensity in oyster toadfish during the month of May $(92 \pm 65)$ and the lowest in July $(1 \pm 1)$.

For spotted seatrout, location CC2 had a more protracted calling season than location CC1 (Fig. 9). The mean calling intensity scores were the highest in August $(43 \pm 32)$ and the lowest in November $(1 \pm 2)$. Temporal heat maps demonstrated a cyclical pattern in spotted seatrout calling at CC1 and CC2 (Fig. 9), similar to the SPL patterns observed in the low frequency SPL band (Fig. 3). These patterns indicate that spotted seatrout began chorusing earlier in the evening and ended later (i.e. longer chorusing dura- tions) in the $1^{\text {st }}$ and $3^{\text {rd }}$ quarter of the lunar cycle compared to the new and full moon phases.

\subsection{Fine-scale spatial mapping of biological sounds in Chechessee Creek}

On 9 August 2016 (i.e. a seasonal timeframe in which spotted seatrout were the dominant soundproducing fish), we conducted 2 passive acoustic surveys at different time periods (18:33-20:00 h, $2.8 \mathrm{~km}$ tow; 20:16-22:21 h, $5.1 \mathrm{~km}$ tow) (Fig. 10). Low frequency SPLs from the fixed recorder at CC1 indicated when sound levels peaked in the evening (Fig. 10A,B). Data collected from our towed acoustic survey displayed 3 general locations of increased low frequency SPL values. Low frequency SPLs reached values as high as $128 \mathrm{~dB}$ re $1 \mu \mathrm{Pa}$ (Fig. 10C,E). Spatial variations in high frequency SPLs were also observed. In particular, one specific location reached levels as high as $127 \mathrm{~dB}$ re $1 \mu \mathrm{Pa}$ (Fig. 10D,F).

On 23 August 2016, we conducted passive acoustic surveys during the day (14:52-15:42 $h$; $3.3 \mathrm{~km}$ tow) and evening (18:44-20:57 $\mathrm{h} ; 5.6 \mathrm{~km}$ tow) (Fig. 11). We conducted these surveys at these different times to emphasize the patterns observed in our stationary recorders: the soundscape exhibited distinct temporal features, and we observed peaks in low frequency SPL in the evening from spotted seatrout spawning aggregations that we did not observe during the day. On this date, low frequency SPLs were lower during the day (max. value: $114 \mathrm{~dB}$ re $1 \mu \mathrm{Pa}$ ) compared to SPLs in the evening (max. value: $124 \mathrm{~dB}$ re $1 \mu \mathrm{Pa}$ ). Locations of increased low frequency SPL values during the evening on this date were similar to the locations noted on 9 August, although the values were generally lower. It is important to note that the lunar phases for these 2 trips were different from 9 August, with the new moon occurring on 11 August and the first quarter on 18 August. On the 23 August trip, spatial variations in high frequency SPLs were also observed, and higher SPLs (as high as $126 \mathrm{~dB}$ re $1 \mu \mathrm{Pa}$ ) appeared in similar locations as reported on 9 August 2016.

On 21 September 2016 (a seasonal timeframe in which spotted seatrout were no longer chorusing), we performed a passive acoustics survey during the evening (16:46-17:16 $h_{\text {i }}$ a $5 \mathrm{~km}$ tow) (Fig. 12). Low frequency SPL values were minimal and did not exceed $111 \mathrm{~dB}$ re $1 \mu \mathrm{Pa}$. On this date, spatial variations in high frequency SPL values were observed, 

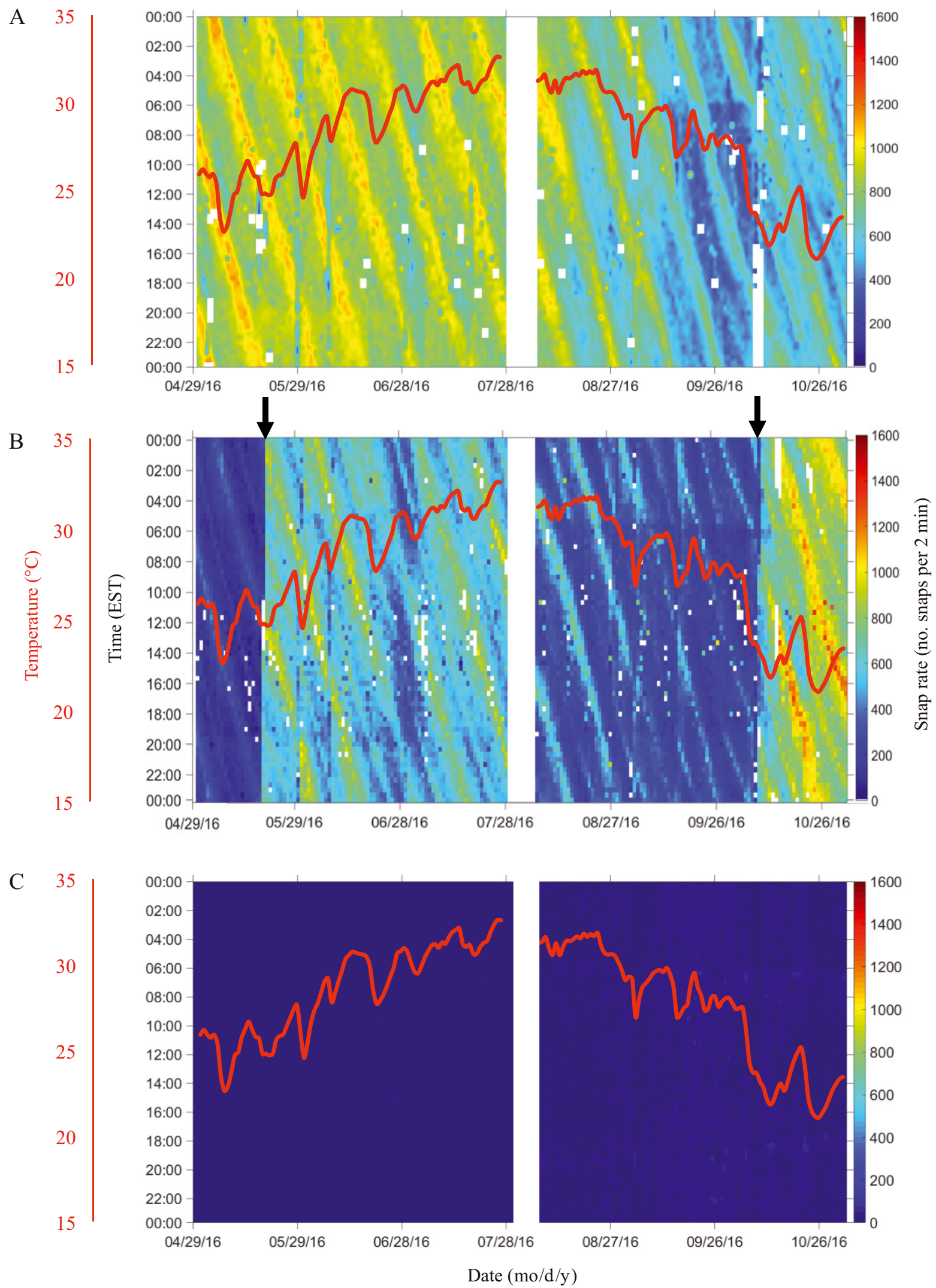

Fig. 7. Snapping shrimp (Alpheus or Synalpheus spp.) snap rates versus date and time at Stns (A) CC1; (B) CC2; and (C) GSP. Warmer colors indicate a higher snap rate. Red line: water temperature. White blocks: time frames in which there was a break for acoustic recorder maintenance or files that were not included in analysis due to noise interference (i.e. anthropogenic or rain). For Stn CC2, left arrow indicates the date (05/18/16) at which the recorder was moved, while right arrow indicates the date (10/08/16) when Hurricane Matthew occurred 


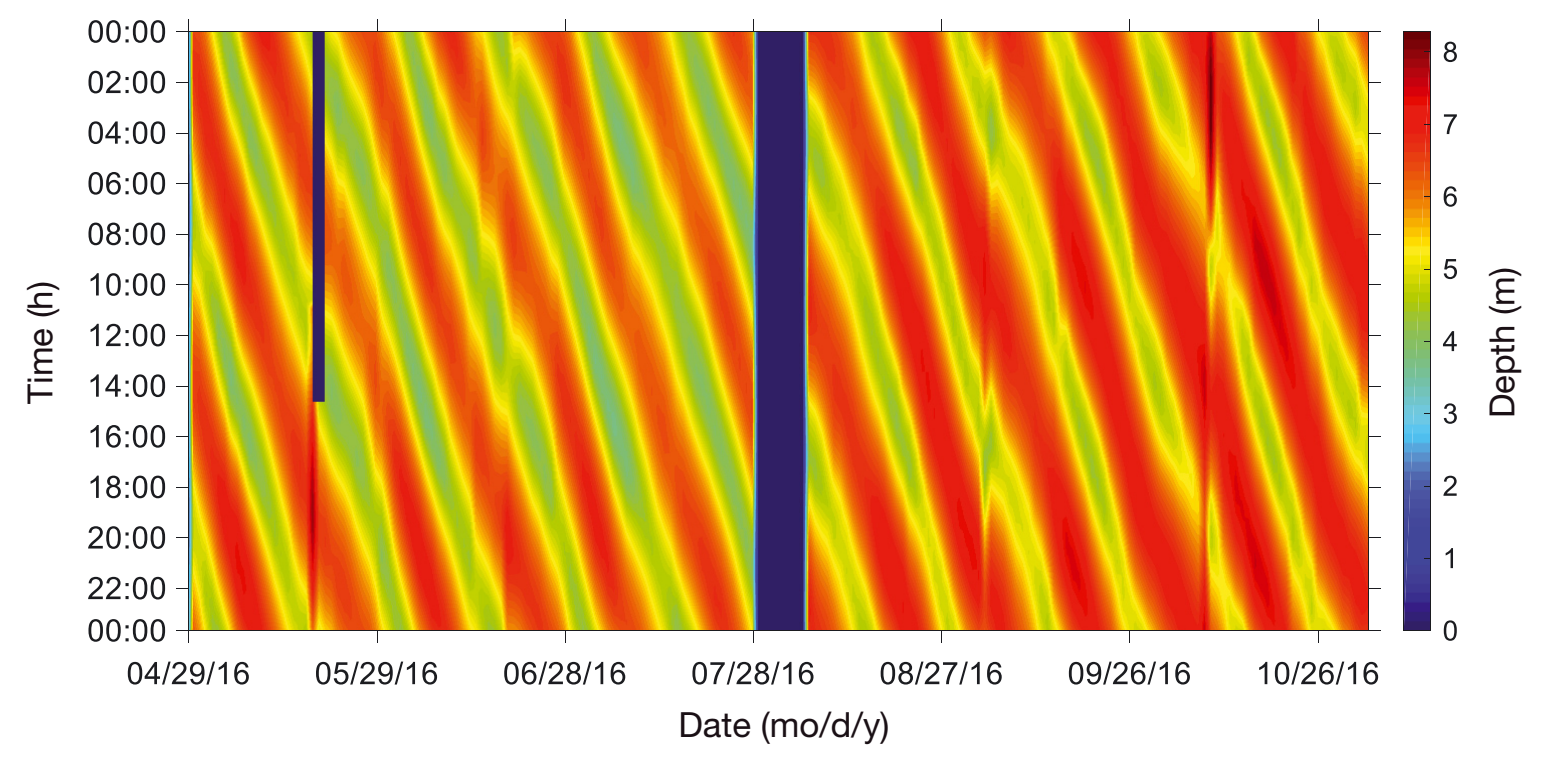

Fig. 8. Depth of the water in Chechessee Creek (Stn CC1) measured every 10 min. Tidal patterns are shown in alternating red (high tide) and green-blue (low tide) lines. The vertical blue lines indicate the time period when the DSG-Ocean recorder was serviced

and higher SPLs (as high as $126 \mathrm{~dB}$ re $1 \mu \mathrm{Pa}$ ) appeared in similar locations as reported on 9 and 23 August 2016.

\section{DISCUSSION}

We found that tidal river estuaries exhibit important spatiotemporal variations in biological sound that may provide information to marine organisms, as well as those who study and manage them. Pairing data collected by both fixed and mobile recording platforms allowed for detailed examination of not only the temporal rhythms of biological sounds, but also the spatial variation of sound throughout the estuary. By assessing SPLs from stationary hydrophones in Chechessee Creek (Stns CC1 and CC2) and the saltwater impoundment (Stn GSP), we were able to examine the acoustic differences between an estuarine creek and a saltwater impoundment, providing some insight into what habitat conditions are necessary to support biological functions such as foraging in snapping shrimp and spawning in fish. Spatial hydrophone surveys provided an organismal perspective of the acoustic gradients present in Chechessee Creek, mimicking the movement and passage of estuarine species through a heterogeneous soundscape. The collection of these data established a framework showing how both fixed and mobile platforms can be used in combination to assess the soundscape variability in an estuary over time and space.

\subsection{Soundscape differences in Chechessee Creek and the saltwater impoundment}

The saltwater impoundment (Stn GSP) exhibited less biological sound than Chechessee Creek (Stns $\mathrm{CC} 1$ and $\mathrm{CC} 2$ ). This impoundment is connected to Chechessee Creek through a small tidal channel with a lock system that can control flow. Water control structures are used to raise and lower the water levels to promote maximum flushing during the tidal cycle, a process which allows movement of estuarine organisms into the GSP. Impoundments are known as areas used to control mosquitoes and attract waterfowl, but these water bodies often have decreased salinity and water exchange compared to estuaries (Montague et al. 1987). A study conducted on a saltwater impoundment in Indian River County, FL, USA, found that impounding a marsh habitat reduced the number of fish species from 16 to 5 (Harrington \& Harrington 1961). The impoundment was quickly invaded by 6 species of gobiids, 5 species of gerreids, and 5 species of sciaenids when reopened (Gilmore et al. 1981). The study explained that impounding the marsh area reduced species diversity, suggesting the negative effects impoundments can have on indigenous species. However, if tidal fluctuations are reintroduced to the area, the impoundment can recover to a more natural ecosystem.

From stocking and survey data, we know that sciaenids were present in the GSP. However, acoustic 

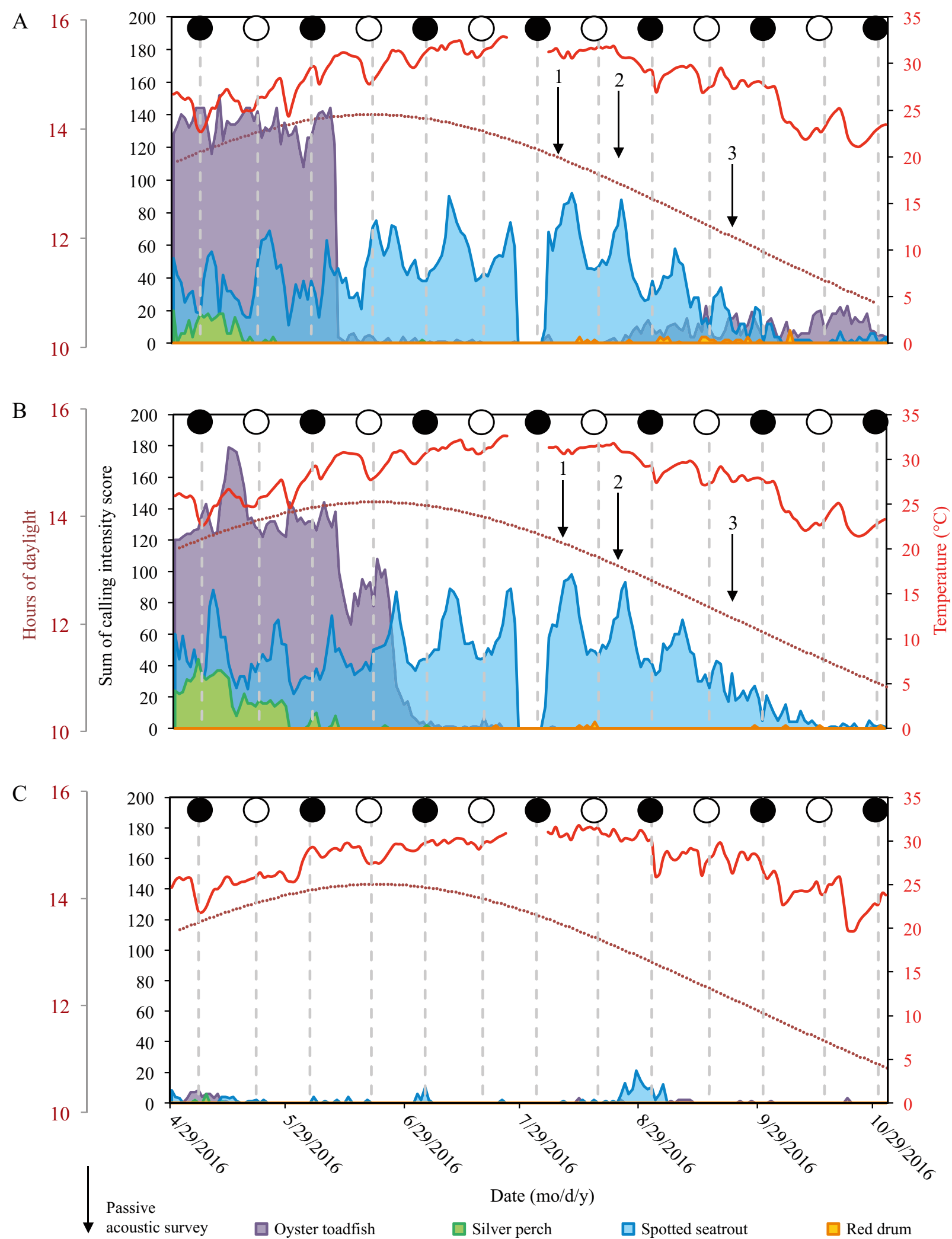

Fig. 9. Seasonal patterns of fish intensity scores tallied per day centered on midnight (i.e. from 12:00 to 11:40 h the next day eastern standard time) at Stns (A) CC1, (B) CC2, and (C) GSP. Also shown are water temperature (red line), hours of daylight (brown dotted line), and new (black circles) and full (white circles) moon phases. Gaps in data indicate timeframes in which there was a break for acoustic recorder maintenance. In (A) and (B), arrows with respective numbers indicate dates on which spatial passive acoustic surveys occurred in Chechessee Creek: 1: 9 August 2016; 2: 23 August 2016; 3: 21 September 2016 
Table 4. General linear model results investigating the influence of specific factors on fish calling in Chechessee Creek and the Great Salt Pond. Values in bold are significant at $\mathrm{p}<0.05$

\begin{tabular}{|lccc|}
\hline & df & $F$ & $p$ \\
\hline Oyster toadfish Opsanus tau & & & \\
Location & 2 & 31.41 & $<\mathbf{0 . 0 1}$ \\
Month & 5 & 35.62 & $<\mathbf{0 . 0 1}$ \\
Lunar phase & 3 & 5.55 & $\mathbf{< 0 . 0 1}$ \\
Tidal range & 1 & 15.75 & $<\mathbf{0 . 0 1}$ \\
Temperature anomaly & 1 & 2.18 & 0.14 \\
$\mathrm{R}^{2}$ & 0.5 & & \\
Spotted seatrout Cynoscion & & & \\
$\quad$ nebulosus & & & \\
Location & 2 & 420.93 & $<\mathbf{0 . 0 1}$ \\
Month & 5 & 55.08 & $<\mathbf{0 . 0 1}$ \\
Lunar phase & 3 & 12.02 & $<\mathbf{0 . 0 1}$ \\
Tidal range & 1 & 26.98 & $<\mathbf{0 . 0 1}$ \\
Temperature anomaly & 1 & 6.22 & $<\mathbf{0 . 0 1}$ \\
$\mathrm{R}^{2}$ & 0.72 & & \\
\hline
\end{tabular}

data indicated that there was minimal snapping shrimp and fish acoustic activity. Compared to the vibrant soundscape of Chechessee Creek, the GSP does not seem to support key acoustic behaviors of soniferous organisms (e.g. foraging of snapping shrimp, spawning of oyster toadfish and spotted seatrout; Patrick \& Palavage 1994, Kupschus 2004, Montie et al. 2015, Rice et al. 2016, Monczak et al. 2017). We speculate that either the GSP was not suitable habitat to support these behaviors or the populations of these organisms were low. Although bottlenose dolphins do not have access to the impoundment, we recorded the call of another apex predator, the American alligator. Both male and female alligators produce a mating bellow, but males preface the call with infrasonic vibrations (Vliet 1989).

\subsection{Temporal variations of the soundscape}

Seasons, lunar cycles, day/night, and tides can influence the acoustic behavior of marine organisms. A study in Charlotte Harbor, Florida, investigated the diel patterns of fish sound production and found that sand seatrout Cynoscion arenarius had a typical evening chorus similar to other sciaenids (Locascio \& Mann 2008). Staaterman et al. (2014) found that high frequency sounds were driven by diel cycles, while low frequency sounds were driven by lunar cycles in the Florida Keys, Florida. In a study conducted in the May River, South Carolina, seasonal, lunar, and daily species-specific patterns in calling were found in sil- ver perch, oyster toadfish, black drum, spotted seatrout, and red drum (Monczak et al. 2017). The seasonal, lunar, and daily patterns of spotted seatrout chorusing in Chechessee Creek resembled the patterns detected in the May River (Monczak et al. 2017). Another notable temporal variation in Chechessee Creek was influenced by the tidal cycle. At both CC1 and CC2, SPLs in the low frequency bandwidth (i.e. fish calling and lower portion of snapping shrimp snaps) and high frequency bandwidth (i.e. snapping shrimp snaps) were highest on the low tide, potentially reflecting the tidal migration of organisms out of the marsh grass and into the main channels of Chechessee Creek (Gibson 2003). GSP did not reflect any temporal variation in sound production.

Snapping shrimp were one of the main acoustic contributors to the soundscape of Chechessee Creek. The most obvious rhythm in snapping shrimp acoustic activity was associated with the tidal cycle; the highest snap rate occurred on the low tide and lowest on the high tide. This pattern may be explained by increased foraging for prey or a change in distribution from the marsh grass and intertidal creeks to the main channel with the ebbing tide (Lehnert \& Allen 2002, Bohnenstiehl et al. 2016, Monczak et al. 2019). The snap detector that we utilized featured a uniform amplitude threshold at each station regardless of environmental conditions. The detection range could vary based upon the ambient noise, but we designed our analyses to minimize this potential.

Our stationary recorders in Chechessee Creek revealed calling of silver perch, oyster toadfish, Atlantic croaker, spotted seatrout, and red drum. We recorded the end of the courtship season of silver perch, which was supported by nearby soundscape studies in the May River estuary (Monczak et al. 2017, 2019). In South Carolina, silver perch typically begin calling in mid-March, when the water temperature reaches $18^{\circ} \mathrm{C}$, and last until early June, when water temperatures consistently exceed $25^{\circ} \mathrm{C}$ (Monczak et al. 2019). Using the long-term data sets of oyster toadfish and spotted seatrout, we detected temporal rhythms in calling that also followed patterns previously reported in the May River estuary (Monczak et al. 2017, 2019). Most notably, spotted seatrout was the dominant low frequency sound-producing species and displayed prominent peaks in chorusing activity and intensity on the first and third quarter of the lunar cycle-similar to findings observed in the May River estuary (Monczak et al. 2017, 2019). With the low tide in the evening, spotted seatrout began calling earlier and ended later (i.e. longer durations), which provides an explanation for the oscillating pattern in our 

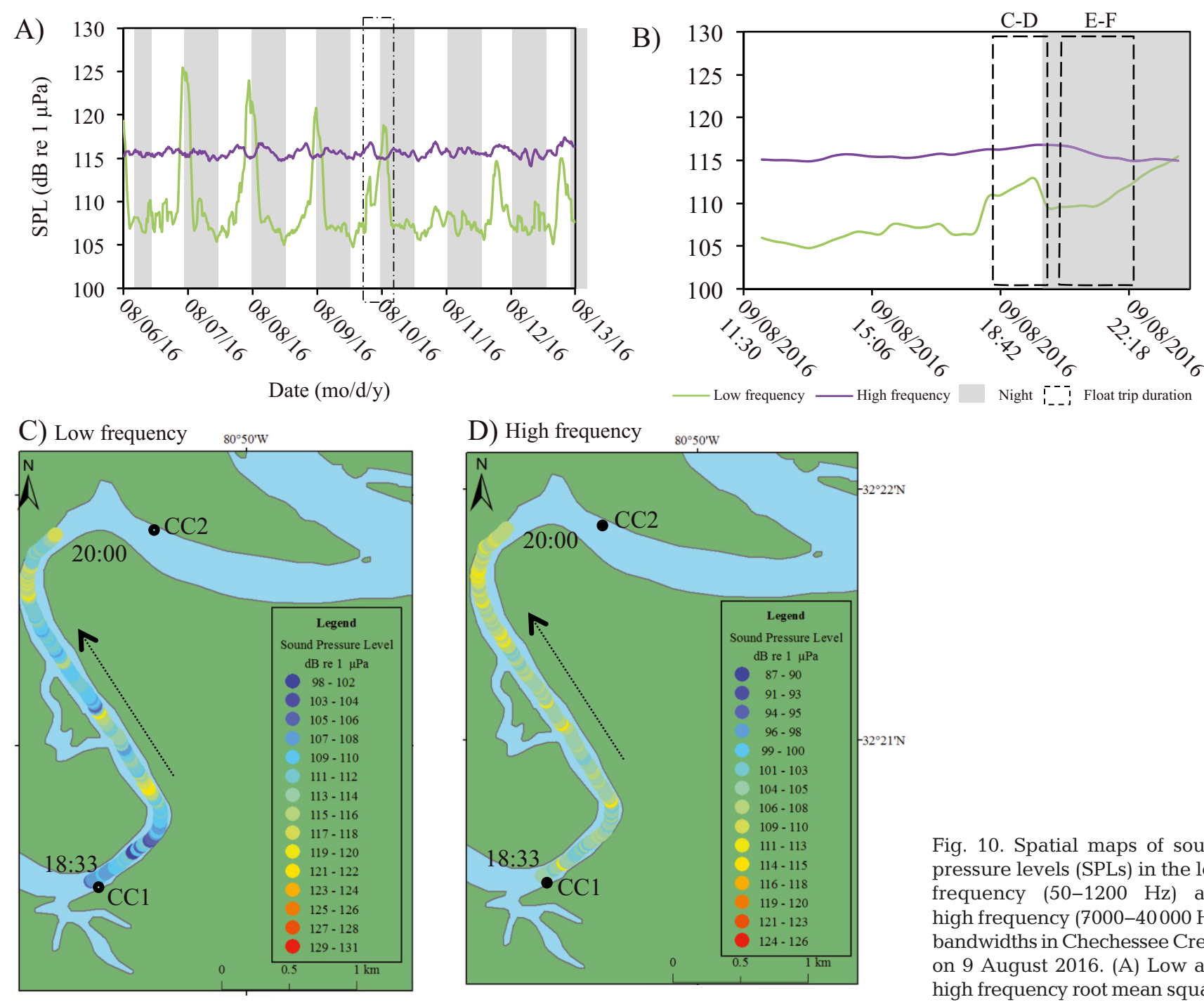

D) High frequency

_Low frequency $ـ$ High frequency $\square$ Night
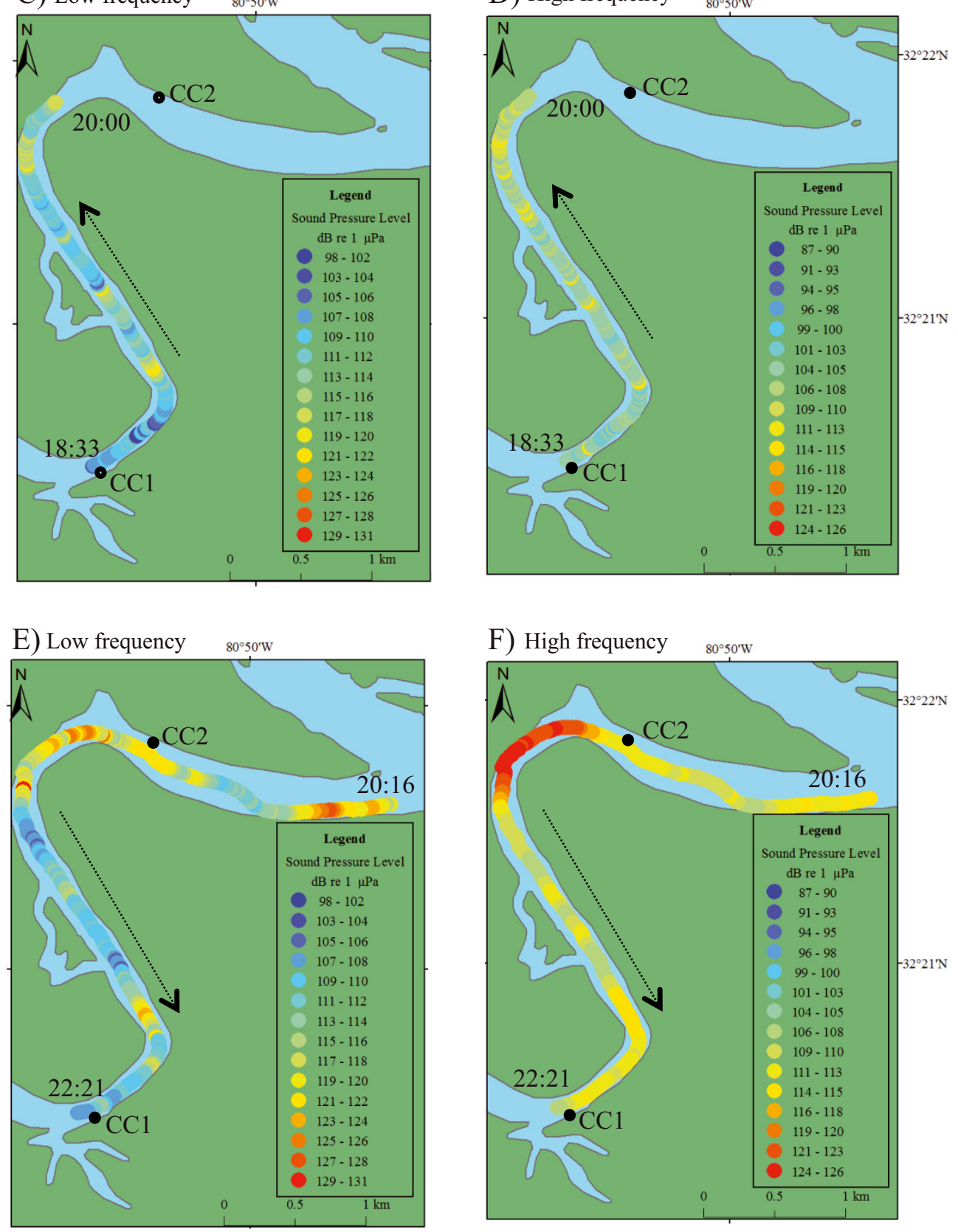

Fig. 10. Spatial maps of sound pressure levels (SPLs) in the low frequency $(50-1200 \mathrm{~Hz})$ and high frequency (7000-40000 Hz) bandwidths in Chechessee Creek on 9 August 2016. (A) Low and high frequency root mean square (rms) SPLs from the stationary recorder at Stn CC1 versus date during the week of the passive acoustic survey. Gray shading: night; rectangular box: the evening of the acoustic survey. (B) Low and high frequency rms SPLs at CC1 versus time on the day of the passive acoustic survey. Rectangular dashed box C-D represents the 'departing' survey, while box E-F represents the 'return' survey. (C) Low and (D) high frequency map of SPLs during the 'departing' survey (1 h 27 min duration); (E) low and (F) high frequency map of SPLs during the 'return' survey ( 2 h $5 \mathrm{~min}$ ). Arrows indicate direction of survey; time stamps reflect beginning and end times. Warmer colors: higher SPL values. Long-term monitoring stations $\mathrm{CC} 1$ and $\mathrm{CC} 2$ are labeled 
A)

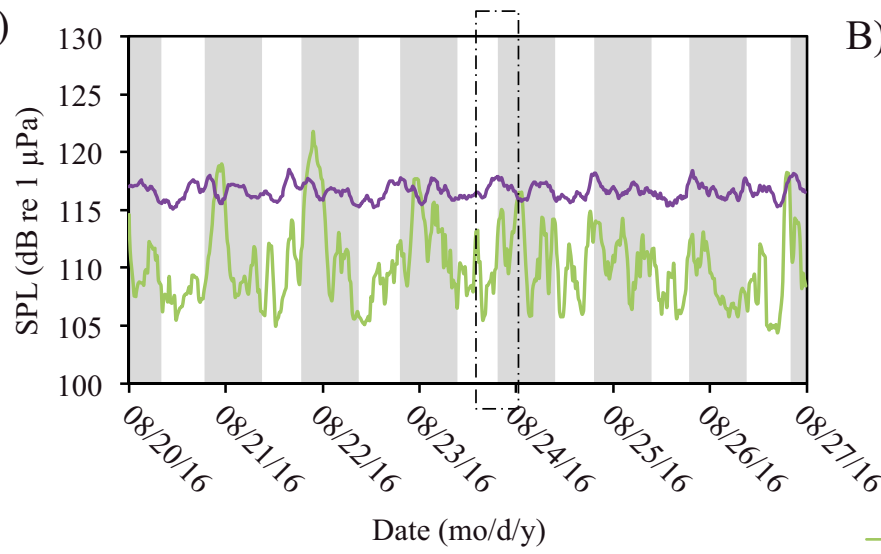

C) Low frequency

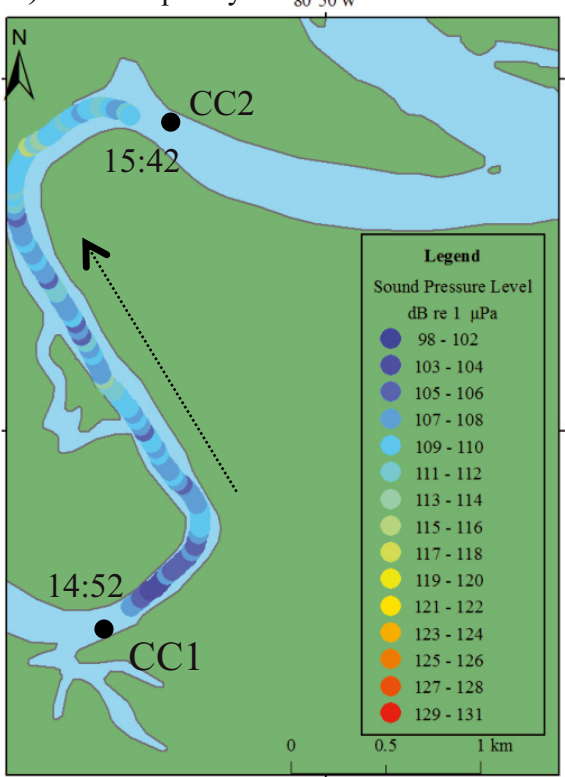

E) Low frequency

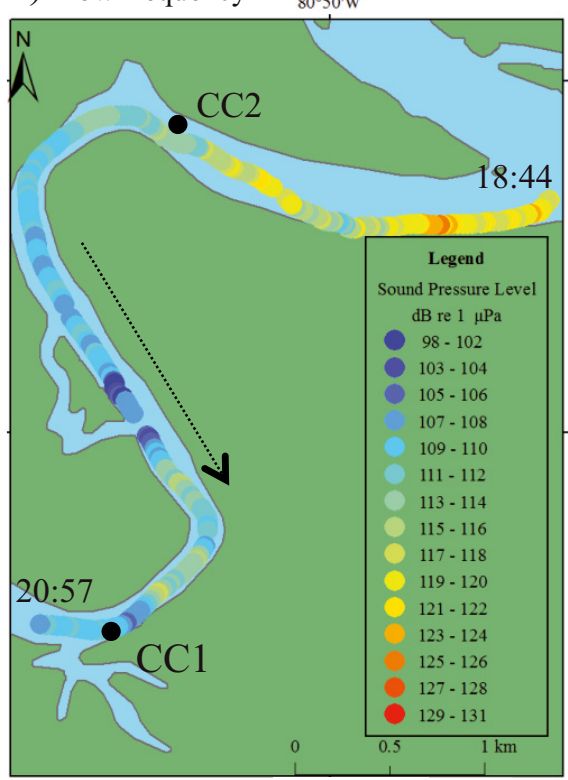

B)

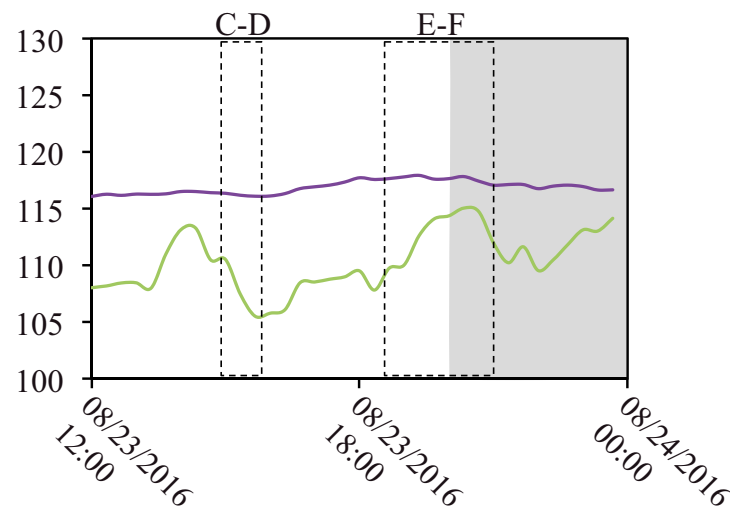

Low frequency _ـ High frequency Night
D) High frequency

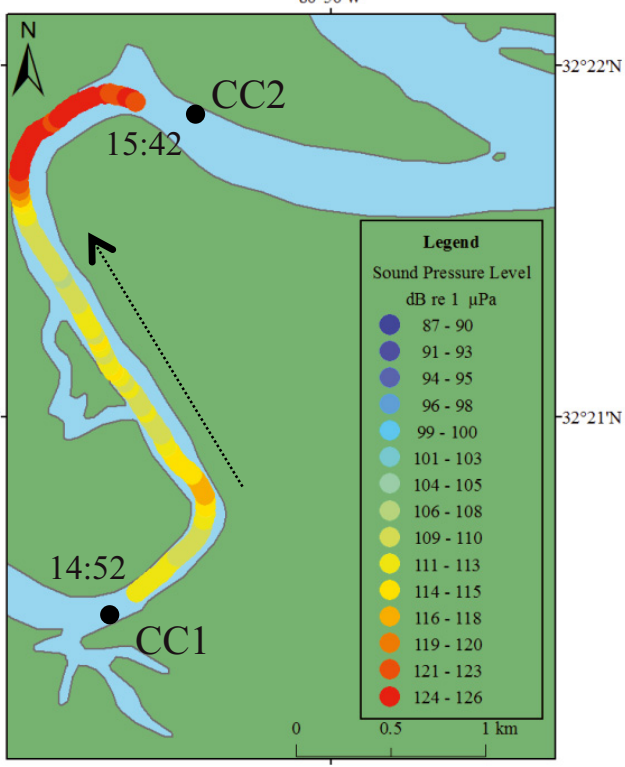

F) High frequency

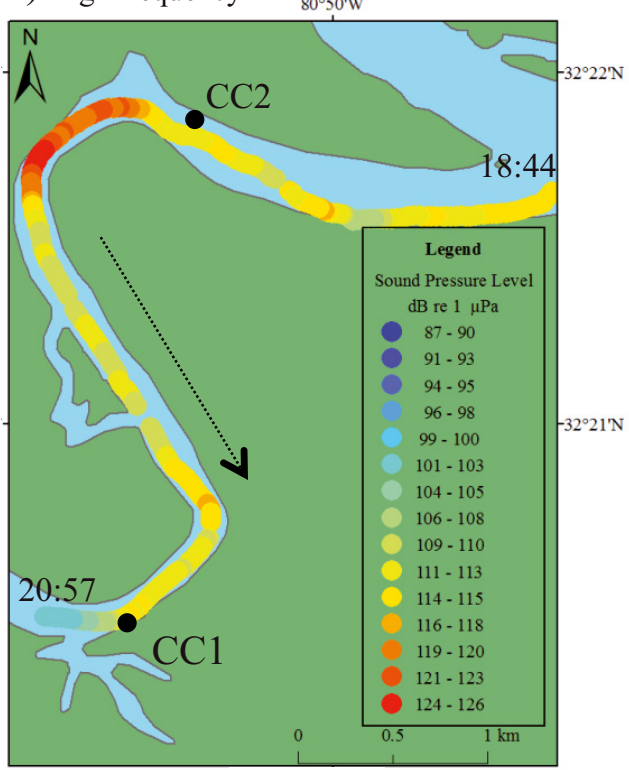

Fig. 11. Spatial maps of sound pressure levels (SPLs) in the low frequency $(50-1200 \mathrm{~Hz})$ and high frequency $(7000-40000 \mathrm{~Hz})$ bandwidths in Chechessee Creek on 23 August 2016. Further details as in Fig. 10, except in $(C, D)$ the 'departing' survey was $1 \mathrm{~h}$ duration; in $(\mathrm{E}, \mathrm{F})$ the 'return' survey was 2 h 13 min duration 
A)

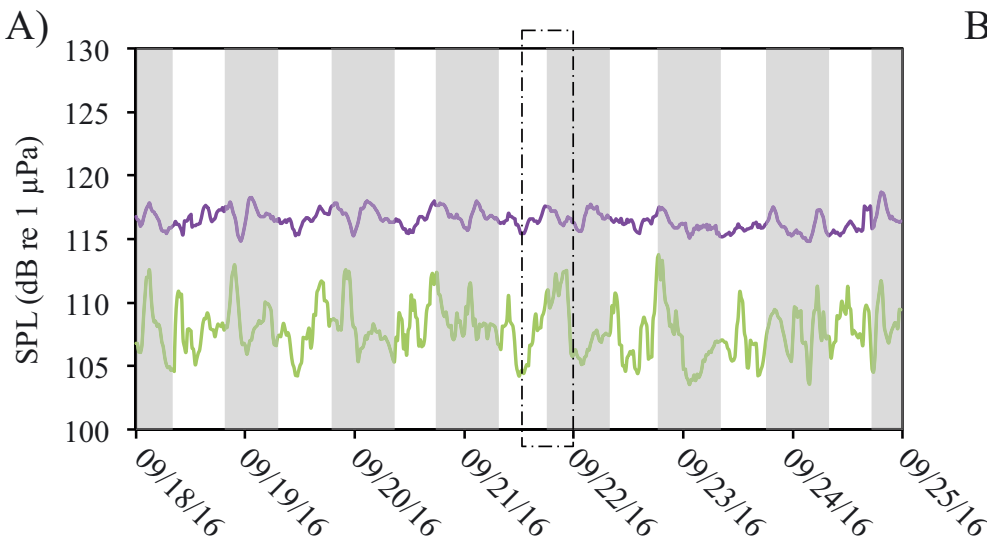

Date $(\mathrm{mo} / \mathrm{d} / \mathrm{y})$
B)

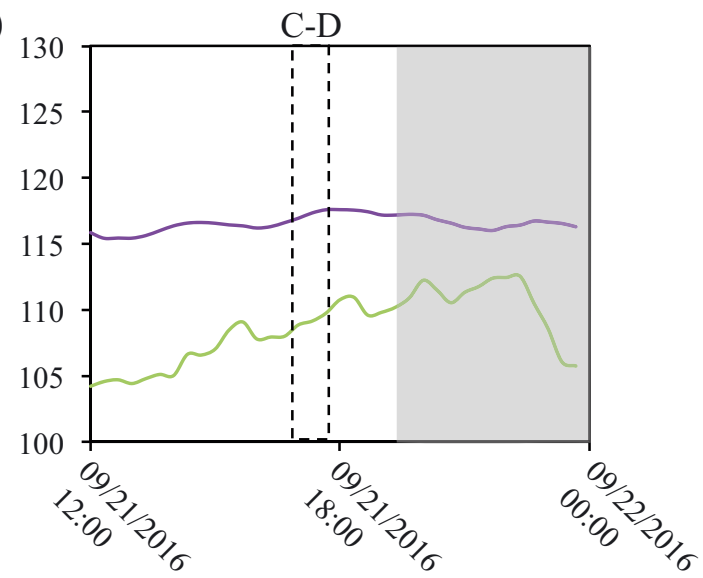

L Low frequency _- High frequency Night

C) Low frequency

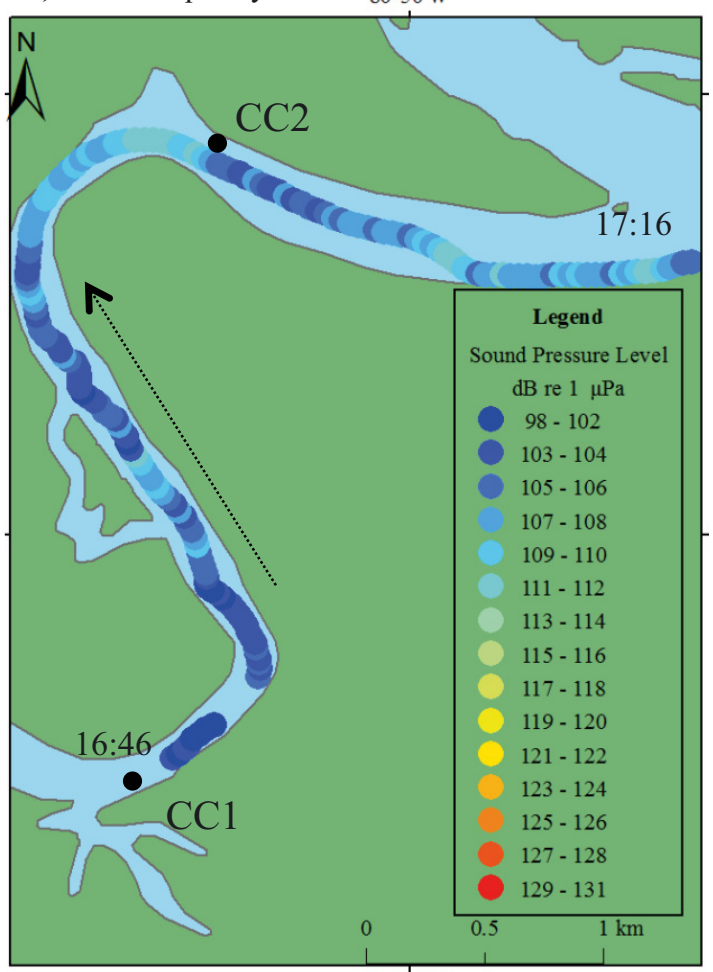

D) High frequency

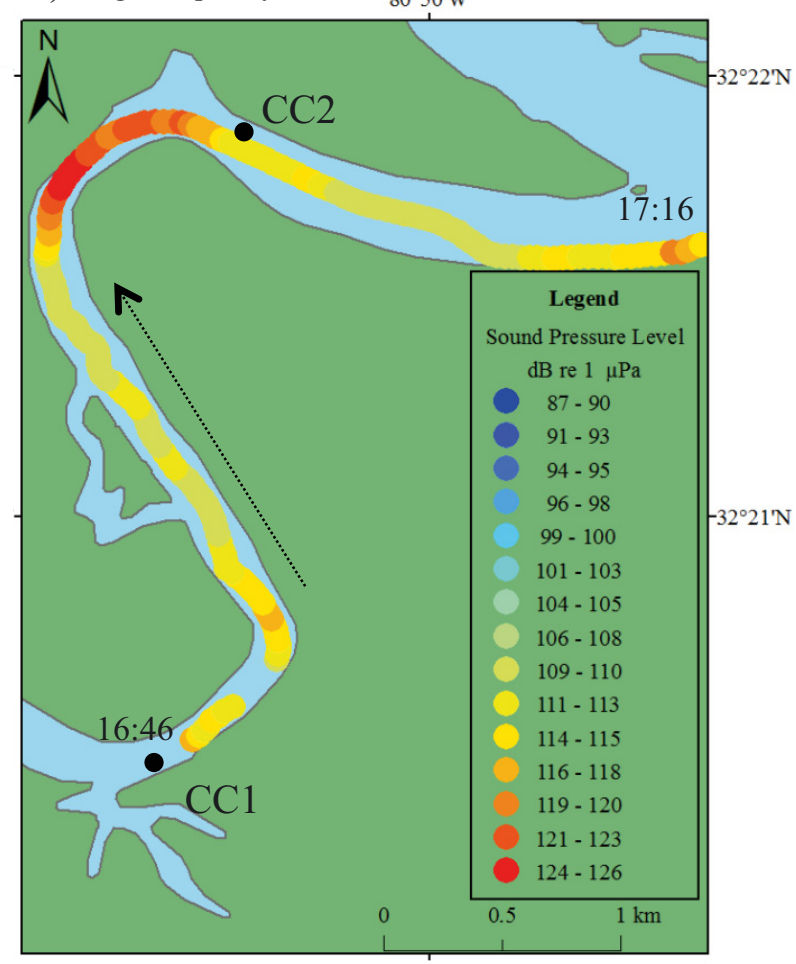

Fig. 12. Spatial maps of sound pressure levels (SPLs) in the low frequency (50-1200 Hz) and high frequency (7000-40000 Hz) bandwidths in Chechessee Creek on 21 September 2016. Further details as in Fig. 10, except that rectangular boxes in (A) and (B) indicate the night of the passive acoustic surveys (30 min duration)

heat maps. It is possible that spotted seatrout spawned more frequently on these evenings, or that the low tide caused the aggregations to be more concentrated due to lower water volume compared to aggregations occurring during high tides. We did not record any red drum chorusing activity in Chechessee Creek, which typically begins later in the summer (August) and lasts until the late fall (November) in South Carolina (Montie et al. 2015, Monczak et al. 2017). Because we sampled throughout the calling and spawning season of red drum, we concluded that red drum spawning did not occur in Chechessee Creek. 


\subsection{Fine-scale spatial variations of sound}

Stationary hydrophones are typically used to demonstrate the overall soundscape of a particular environment. While this tool is necessary for understanding temporal rhythms, towed hydrophones or autonomous vehicles can assist in understanding the spatial heterogeneity of sound (Holt 2008, DeAngelis et al. 2017, Lillis et al. 2018). These data can provide an understanding of what organisms experience acoustically as they move through an estuary. In fact, there is some evidence that acoustic gradients serve as settlement or spawning cues to organisms that pass through the soundscape. For example, in the Pamlico Sound, North Carolina, oyster reefs were found to be significantly louder than soft-bottom habitats with supporting research that suggested that these acoustic differences could serve as a cue for planktonic larva to settle (Lillis et al. 2014b). Several studies have also investigated the importance of acoustic variation around coral reefs for larval fish recruitment. One study conducted around 7 small islands in Bohol, Philippines, found a correlation between reef quality and sound produced, suggesting that healthier reefs are more likely to recruit larval fishes because they can be heard from a greater distance (Piercy et al. 2014). Estuarine larval fish may congregate in areas with higher sound levels because these levels may indicate more resources, or they could avoid these areas because these levels may indicate the presence of predators.

In our study, the SPLs in the high frequency bandwidth were highest near an anti-erosion wall made from large rocks. Snapping shrimp prefer areas with crevices and holes (e.g. oyster reefs and rocky substrate) (Johnson et al. 1947), and this artificial structure provided this type of habitat. Oyster reefs have distinct soundscapes (Lillis et al. 2013, 2014a,b), and they serve as significant habitats in estuaries because of the structure and resources they provide for both benthic and nektonic organisms (Lehnert \& Allen 2002, Kingsley-Smith et al. 2012). More analyses would be necessary to determine how anthropogenic structures, such as the anti-erosion wall in Chechessee Creek, serve as habitats for larval settlement and nekton recruitment.

Estuaries in the southeast USA are important spawning grounds for many sciaenid species including silver perch, spotted seatrout, and red drum (Mok \& Gilmore 1983, Montie et al. 2015, Monczak et al. 2017). In these species, it is thought that males produce courtship calls to attract females to a spawning location (Roumillat \& Brouwer 2004, Ramcharitar et al. 2006, Walters et al. 2009). In Chechessee Creek, we discovered that sound levels in the low frequency bandwidth (i.e. indicative of spotted seatrout chorusing) were spatially heterogeneous and certain areas (i.e. near the anti-erosion wall and mouth of Chechessee Creek) experienced higher sound levels. It is very possible that females swim through estuaries listening to male courtship calls and selecting the loudest aggregations. As females and males detect these calls, the aggregations may grow and sound may facilitate this hyper-aggregating behavior and coordinate mass spawning. As emphasized throughout our results, timing is essential in understanding fish sound production rates. However, areas without fish calling may not necessarily indicate a low fish presence but rather fish not engaging in this type of behavior. This conundrum is an important limitation to consider when conducting these surveys and drawing conclusions. Combining passive acoustic surveys with active acoustics may provide a means to understand call dynamics, behavior, and fish numbers (Erisman \& Rowell 2017, Zemeckis et al. 2019).

As supported by data collected from our stationary recorders, spotted seatrout chorusing is influenced by temporal variables such as season, lunar cycle, time of day, and tidal cycle. By conducting 3 passive acoustic surveys over different periods, we were able to determine hotspots of chorusing activity. Chorusing was most notable on 9 August, a survey that occurred in the midst of the spawning season, closest to the first quarter of the lunar cycle, and during the evening. The 2 other hydrophone surveys $(23$ August and 21 September) did not provide as much insight into the spatial distribution of aggregations because they were completed during a time period with less calling and chorusing. Of course, a limitation of towed surveys is flow noise, but we did minimize this variable by using a trolling motor and towing in the direction of the tidal flow. If resources and time were available, a finer-scale stationary array could be used; this would increase spatial resolution but not sacrifice temporal resolution. Nonetheless, our findings do emphasize the importance of understanding the temporal rhythms of target species with long-term, stationary platforms before attempting to understand spatial patterns with towed hydrophones.

\subsection{Can soundscapes be used to gauge estuarine health?}

Previous studies have utilized mobile platforms to determine spatial variation in sound (Holt 2008, Wall et al. 2012, DeAngelis et al. 2017, Lillis et al. 2018, 
Zemeckis et al. 2019), but combining this approach with stationary recorders is innovative for estuarine ecosystems. A recent study by Lillis et al. (2018) in Pamlico Sound, North Carolina, and St. John, US Virgin Islands, examined the method of conducting drifting hydrophone surveys over oyster reefs and coral reefs to highlight the connection between habitat and sound levels. Results indicated that drifting acoustic recorders were able to detect small-scale variations in the soundscape and that both coral and oyster reefs significantly elevated the sound levels. This pattern is consistent with the mapping results that we found in Chechessee Creek. We argue again that both fixed and mobile platforms are best used in tandem for finescale spatial analysis because species exhibit rhythmic patterns in sound production that are tuned to temporal and environmental variables. If resources are available, an alternative approach, as we discussed previously, is to increase the number of fixed recording stations to improve spatial resolution, while retaining temporal resolution. Nonetheless, understanding the spatial complexity of soundscapes must be framed within a temporal and environmental context.

Collectively, these findings pose a very interesting question in marine ecology - Are healthier habitats or ecosystems biologically louder? Costanza \& Mageau (1999) discuss a healthy ecosystem as one that maintains its structure (organization) and function (vigor) over time when faced with external stress (resilience). As we illustrated in the current study, soundscape characterization can provide acoustic behavior measurements at multiple levels of biological organization. This approach makes it possible to eavesdrop on key behaviors or functions that can change rapidly or gradually in response to environmental changes and human use, thus providing a measure of resilience or shifting baselines in the face of a globally changing environment. Collectively, we can measure these biological sounds as an overall intensity or SPL. In the present study, we did find higher SPLs in Chechessee Creek compared to the levels present in the saltwater impoundment, which provides some support for this hypothesis. However, these are very different habitats (creek versus an impoundment), and a more robust study would involve similar estuaries with a control site and sites with various levels of degradation.

More extensive mapping studies with traditional biodiversity surveys will be necessary to examine the correlation between habitat health, biodiversity, and sound levels. Recently, researchers have applied soundscape metrics such as the Acoustic Complexity Index and Acoustic Entropy to marine ecosystems to determine if these indices correlate with biodiversity and habitat complexity (e.g. Kaplan et al. 2015, Staaterman et al. 2017, Bohnenstiehl et al. 2018). We argue that studying soundscapes could provide a broader understanding of estuarine health because this approach acquires behavioral data at multiple levels of biological complexity (i.e. from snapping shrimp to fish to marine mammals) at fine spatial scales and time series that range from minutes to years.

Acknowledgements. This work was supported primarily by the Lowcountry Institute and an ASPIRE II grant from the Office of the Vice President for Research at USC. We thank Dr. Chris Marsh for discussion of original ideas and helping with funding organization. In addition, we thank Jake Morgenstern, Hannah Nylander-Asplin, and Debra Albanese for assistance in data analysis and field work.

\section{LITERATURE CITED}

Bohnenstiehl DR, Lillis A, Eggleston DB (2016) The curious acoustic behavior of estuarine snapping shrimp: temporal patterns of snapping shrimp sound in sub-tidal oyster reef habitat. PLOS ONE 11:e0143691

*Bohnenstiehl DR, Lyon RP, Caretti ON, Ricci SW, Eggleston DB (2018) Investigating the utility of ecoacoustic metrics in marine soundscapes. J Ecoacoustics 2:R1156L. https:// pdfs.semanticscholar.org/a3a9/628f66012af251bff71c3eb 77dbff89973fa.pdf

Costanza R, Mageau M (1999) What is a healthy ecosystem? Aquat Ecol 33:105-115

* DeAngelis AI, Valtierra R, Van Parijs SM, Cholewiak D (2017) Using multipath reflections to obtain dive depths of beaked whales from a towed hydrophone array. J Acoust Soc Am 142:1078-1087

Eggleston DB, Lipcius RN, Marshall LS, Ratchford SG (1998) Spatiotemporal variation in postlarval recruitment of the Caribbean spiny lobster in the central Bahamas: lunar and seasonal periodicity, spatial coherence, and wind forcing. Mar Ecol Prog Ser 174:33-49

* Erisman BE, Rowell TJ (2017) A sound worth saving: acoustic characteristics of a massive fish spawning aggregation. Biol Lett 13:20170656

*Ghasemi A, Zahediasl S (2012) Normality tests for statistical analysis: a guide for non-statisticians. Int $\mathrm{J}$ Endocrinol Metab 10:486-489

Gibson R (2003) Go with the flow: tidal migrations in marine animals. Hydrobiologia 503:153-161

*Gilmore RG, Cooke DW, Donohoe CJ (1981) A comparison of the fish populations and habitat in open and closed salt marsh impoundments in east-central Florida. Northeast Gulf Sci 5:25-37

*Harrington RW, Harrington ES (1961) Food selection among fishes invading a high subtropical salt marsh: from onset of flooding through the progress of a mosquito brood. Ecology 42:646-666

Hendry JL (2004) The ontogeny of echolocation in Atlantic bottlenose dolphins (Tursiops truncatus). PhD dissertation, University of Southern Mississippi, Hattiesburg, MS

Herzing D (1996) Vocalizations and associated underwater behavior of free-ranging Atlantic spotted dolphins and bottlenose dolphins. Aquat Mamm 22:61-79 
Holt SA (2008) Distribution of red drum spawning sites identified by a towed hydrophone array. Trans Am Fish Soc 137:551-561

Janik VM (2000) Whistle matching in wild bottlenose dolphins (Tursiops truncatus). Science 289:1355-1357

Johnson MW, Everest FA, Young RW (1947) The role of snapping shrimp (Crangon and Synalpheus) in the production of underwater noise in the sea. Biol Bull 93: 122-138

Kaplan MB, Mooney TA, Partan J, Solow AR (2015) Coral reef species assemblages are associated with ambient soundscapes. Mar Ecol Prog Ser 533:93-107

Kim HY (2013) Statistical notes for clinical researchers: assessing normal distribution using skewness and kurtosis. Restor Dent Endod 38:52-54

Kingsley-Smith PR, Joyce RE, Arnott SA, Roumillat WA, McDonough CJ, Reichert MJM (2012) Habitat use of intertidal eastern oyster (Crassostrea virginica) reefs by nekton in South Carolina estuaries. J Shellfish Res 31: 1009-1021

Krause B, Gage SH, Joo W (2011) Measuring and interpreting the temporal variability in the soundscape at four places in Sequoia National Park. Landsc Ecol 26: 1247-1256

Kupschus S (2004) A temperature-dependent reproductive model for spotted seatrout (Cynoscion nebulosus) explaining spatio-temporal variations in reproduction and young-of-the-year recruitment in Florida estuaries. ICES J Mar Sci 61:3-11

Lehnert RL, Allen DM (2002) Nekton use of subtidal oyster shell habitat in a southeastern US estuary. Estuaries 25: 1015-1024

Lillis A, Eggleston DB, Bohnenstiehl DR (2013) Oyster larvae settle in response to habitat-associated underwater sounds. PLOS ONE 8:e79337

Lillis A, Eggleston DB, Bohnenstiehl DR (2014a) Estuarine soundscapes: distinct acoustic characteristics of oyster reefs compared to soft-bottom habitats. Mar Ecol Prog Ser 505:1-17

Lillis A, Eggleston DB, Bohnenstiehl DR (2014b) Soundscape variation from a larval perspective: the case for habitat-associated sound as a settlement cue for weakly swimming estuarine larvae. Mar Ecol Prog Ser 509: $57-70$

Lillis A, Bohnenstiehl DR, Eggleston DB (2015) Soundscape manipulation enhances larval recruitment of a reefbuilding mollusk. PeerJ 3:e999

Lillis A, Caruso F, Mooney TA, Llopiz J, Bohnenstiehl D, Eggleston DB (2018) Drifting hydrophones as an ecologically meaningful approach to underwater soundscape measurement in coastal benthic habitats. J Ecoacoustics 2:STBDH1. https://jea.jams.pub/article/ $2 / 1 / 44$

Locascio JV, Mann DA (2008) Diel periodicity of fish sound production in Charlotte Harbor, Florida. Trans Am Fish Soc 137:606-615

Lowerre-Barbieri SK, Barbieri LR, Flanders JR, Woodward AG, Cotton CF, Knowlton MK (2008) Use of passive acoustics to determine red drum spawning in Georgia waters. Trans Am Fish Soc 137:562-575

Luczkovich JJ, Sprague MW, Johnson SE, Pullinger RC (1999) Delimiting spawning areas of weakfish, $C y$ noscion regalis (Family Sciaenidae) in Pamlico Sound, North Carolina using passive hydroacoustic surveys. Bioacoustics 10:143-160
Luczkovich JJ, Mann DA, Rountree RA (2008a) Passive acoustics as a tool in fisheries science. Trans Am Fish Soc 137:533-541

*Luczkovich JJ, Pullinger RC, Johnson SE, Sprague MW (2008b) Identifying sciaenid critical spawning habitats by the use of passive acoustics. Trans Am Fish Soc 137: 576-605

Mann DA, Casper BM, Boyle KS, Tricas TC (2007) On the attraction of larval fishes to reef sounds. Mar Ecol Prog Ser 338:307-310

McCowan B, Reiss D (2001) The fallacy of 'signature whistles' in bottlenose dolphins: a comparative perspective of 'signature information' in animal vocalizations. Anim Behav 62:1151-1162

* Merchant ND, Fristrup KM, Johnson MP, Tyack PL, Witt MJ, Blondel P, Parks SE (2015) Measuring acoustic habitats. Methods Ecol Evol 6:257-265

Mok HK, Gilmore RG (1983) Analysis of sound production in estuarine aggregations of Pogonias cromis, Bairdiella chrysoura, and Cynoscion nebulosus (Sciaenidae). Bull Inst Zool Acad Sin 22:157-186

* Monczak A, Berry A, Kehrer C, Montie EW (2017) Longterm acoustic monitoring of fish calling provides baseline estimates of reproductive timelines in the May River estuary, southeastern USA. Mar Ecol Prog Ser 581:1-19

*Monczak A, Mueller C, Miller ME, Ji Y, Borgianini SA, Montie EW (2019) Sound patterns of snapping shrimp, fish, and dolphins in an estuarine soundscape of the southeastern USA. Mar Ecol Prog Ser 609:49-68

* Montague C, Zale A, Percival H (1987) Ecological effects of coastal marsh impoundments: a review. Environ Manage 11:743-756

Montie EW, Vega S, Powell M (2015) Seasonal and spatial patterns of fish sound production in the May River, South Carolina. Trans Am Fish Soc 144:705-716

*Montie EW, Kehrer C, Yost J, Brenkert K, O'Donnell T, Denson MR (2016) Long-term monitoring of captive red drum Sciaenops ocellatus reveals that calling incidence and structure correlate with egg deposition. J Fish Biol 88: 1776-1795

*Montie EW, Hoover M, Kehrer C, Yost J, Brenkert K, O'Donnell T, Denson MR (2017) Acoustic monitoring indicates a correlation between calling and spawning in captive spotted seatrout (Cynoscion nebulosus). PeerJ 5:e2944

Patrick R, Palavage DM (1994) The value of species as indicators of water quality. Proc Acad Nat Sci Phila 145: 55-92

*Piercy JJB, Codling EA, Hill AJ, Smith DJ, Simpson SD (2014) Habitat quality affects sound production and likely distance of detection on coral reefs. Mar Ecol Prog Ser 516:35-47

* Pijanowski BC, Farina A, Gage SH, Dumyahn SL, Krause BL (2011) What is soundscape ecology? An introduction and overview of an emerging new science. Landsc Ecol 26: 1213-1232

* Ramcharitar J, Gannon DP, Popper AN (2006) Bioacoustics of fishes of the Family Sciaenidae (croakers and drums). Trans Am Fish Soc 135:1409-1431

* Ricci SW, Eggleston DB, Bohnenstiehl DR, Lillis A (2016) Temporal soundscape patterns and processes in an estuarine reserve. Mar Ecol Prog Ser 550:25-38

* Rice AN, Morano JL, Hodge KB, Muirhead CA (2016) Spatial and temporal patterns of toadfish and black drum 
chorusing activity in the South Atlantic Bight. Environ Biol Fishes 99:705-716

Rosenblatt AE, Heithaus MR, Mazzotti FJ, Cherkiss M, Jeffery BM (2013) Intra-population variation in activity ranges, diel patterns, movement rates, and habitat use of American alligators in a subtropical estuary. Estuar Coast Shelf Sci 135:182-190

Roumillat WA, Brouwer MC (2004) Reproductive dynamics of female spotted seatrout (Cynoscion nebulosus) in South Carolina. Fish Bull 102:473-487

Rountree RA, Gilmore RG, Goudey CA, Hawkins AD, Luczkovich JJ, Mann DA (2006) Listening to fish-applications of passive acoustics to fisheries science. Fisheries (Bethesda, Md) 31:433-446

Sprague MW (2000) The single sonic muscle twitch model for the sound-production mechanism in the weakfish Cynoscion regalis. J Acoust Soc Am 108:2430-2437

Staaterman E, Paris CB, DeFerrari HA, Mann DA, Rice AN, D'Alessandro EK (2014) Celestial patterns in marine soundscapes. Mar Ecol Prog Ser 508:17-32

Staaterman E, Ogburn MB, Altieri AH, Brandl SJ and others (2017) Bioacoustic measurements complement visual

Editorial responsibility: Elliott Hazen,

Pacific Grove, California, USA biodiversity surveys: preliminary evidence from four shallow marine habitats. Mar Ecol Prog Ser 575:207-215

Tavolga WN (1958) Underwater sounds produced by two species of toadfish Opsanus tau and Opsanus beta. Bull Mar Sci 8:278-284

Vergne AL, Pritz MB, Mathevon N (2009) Acoustic communication in crocodilians: from behaviour to brain. Biol Rev Camb Philos Soc 84:391-411

Vliet K (1989) Social displays of the American alligator (Alligator mississippiensis). Integr Comp Biol 29:1019-1031

Wall C, Lembke C, Mann DA (2012) Shelf-scale mapping of sound production by fishes in the eastern Gulf of Mexico, using autonomous glider technology. Mar Ecol Prog Ser 449:55-64

*Walters S, Lowerre-Barbieri S, Bickford J, Mann D (2009) Using a passive acoustic survey to identify spotted seatrout spawning sites and associated habitat in Tampa Bay, Florida. Trans Am Fish Soc 138:88-98

Zemeckis DR, Dean MJ, DeAngelis AI, Van Parijs SM and others (2019) Identifying the distribution of Atlantic cod spawning using multiple fixed and glider-mounted acoustic technologies. ICES J Mar Sci 76:1610-1625

Submitted: October 4, 2019 ; Accepted: May 18, 2020

Proofs received from author(s): July 3, 2020 